\title{
Electrostatic Assembly Technique for Novel Composites Fabrication
}

\author{
Hiroyuki Muto ${ }^{1,2, *}$, Atsushi Yokoi ${ }^{1}$ and Wai Kian Tan ${ }^{1, *}$ iD \\ 1 Institute of Liberal Arts and Sciences, Toyohashi University of Technology, Toyohashi, Aichi 441-8580, Japan; \\ yokoi@ion.ee.tut.ac.jp \\ 2 Department of Electrical \& Electronics Information Engineering, Toyohashi University of Technology, \\ Toyohashi, Aichi 441-8580, Japan \\ * $\quad$ Correspondence: muto@ee.tut.ac.jp (H.M.); tan@las.tut.ac.jp (W.K.T.); Tel.: +81-532-44-6808 (W.K.T.)
}

Received: 25 September 2020; Accepted: 15 October 2020; Published: 20 October 2020

Abstract: Electrostatic assembly is one of the bottom-up approaches used for multiscale composite fabrication. Since its discovery, this method has been actively used in molecular bioscience as well as materials design and fabrication for various applications. Despite the recent advances and controlled assembly reported using electrostatic interaction, the method still possesses vast potentials for various materials design and fabrication. This review article is a timely revisit of the electrostatic assembly method with a brief introduction of the method followed by surveys of recent advances and applications of the composites fabricated. Emphasis is also given to the significant potential of this method for advanced materials and composite fabrication in line with sustainable development goals. Prospective outlook and future developments for micro-/nanocomposite materials fabrication for emerging applications such as energy-related fields and additive manufacturing are also mentioned.

Keywords: electrostatic assembly; polyelectrolytes; composites; ceramics; polymers; additive manufacturing

\section{Introduction}

Nanomaterials exhibit unique properties that are not seen in bulk materials, and this has led to an increase in the development of nanocomposites for various applications. In composite materials design and fabrication, the approach used is either a top-down or bottom-up approach [1,2]. However, the bottom-up approach offers better flexibility in terms of dimension control, shape ability, and surface-charge modification to achieve desired properties and functionalities [3]. An example of a bottom-up approach in materials design is the electrostatic assembly (EA) method. Caruso first reported the formation of multilayer silica nanoparticles on polystyrene latex using the EA method in 1998 [4]. Since then, the EA method has been widely used for the design and fabrication of materials such as bio-components [5-7], polymers [8,9], inorganic materials [1,10], and carbon-based materials such as graphene and fullerene [11,12].

In this review, a brief overview of an electrostatic assembly is first described, followed by a comprehensive survey of the current progress in composite materials design via the EA method as well as its prospective outlook for future development. Emphasis on emerging applications using EA assembly is given in this review.

\subsection{The EA Method}

In earlier days, the EA method involved the use of the Langmuir-Boldgett (LB) technique where monolayers generated on water were transported onto a solid supporting structure. With the limitations in equipment, substrate size, as well as film quality of the LB technique, the self-assembly 
of films using covalent and coordination chemistry was developed. However, this technique was only applicable for certain classes of organic materials with limited design flexibility, and a high-quality multilayered structure cannot be achieved. To achieve a good nano-architectured film yield regardless of the substrate topology and nature, a suitable alternative is to employ the electrostatic attraction of molecules with opposite charges as a driving motion for the multilayer and nanoarchitecture build up [13]. Decher et al. first reported the formation of one or multiple layered composite films (coatings) via a layer-by-layer (LbL) adsorption of polyelectrolytes in aqueous solution. The basic principle of this technique involves the repulsion of equally charged molecules (induced using polyelectrolytes) as well as the attraction and adsorption of oppositely charged molecules to the initial molecule leading to form well controlled multilayer structured films after several cycles [14].

Subsequently, many studies have been reported using the EA method and LbL assembly for various applications. The reason for this boom is the feasibility of using the EA method for controlled decoration of desired additives at the nano and micro levels irrespective of the object's shape and dimensions, which is not achievable using conventional mixing methods [1]. The attractive features of this approach include the controllability of additive coverage percentage on a primary particle [1] and controllability of multiple-component layered films formation with good precision [7,15]. Studies focusing on biomaterials and biomedicine for drug delivery and cell cultivation have been reported [16-18]. As the awareness for achieving the sustainability development goals (SDGs) began to grow in our daily lives, the development of materials for sustainable-related technologies such as renewable energies (fuel cells, solar cells), water treatment, efficient energy storage systems (batteries and capacitors), and additive manufacturing have been deemed as emerging technologies and taken the center stage in research and development. Low environmental load processes have been recognized as a way of achieving SDGs through efficient energy usage and the effective utilization of natural resources without leaving heavy footprints on the environment. Given that the EA method is a green process approach, it is expected to play an important role in materials design to achieve the SDGs.

\subsection{Outline of this Review}

This review focuses on and revisits the applicability and versatility of the EA method for the assembly of composite materials. The fundamental as well as parameters that affect the assembly process are also briefly described to provide an insight into this technique for the readers. Despite the advancements in EA and LbL methods over the years, most study reports are based on film formation for the design of supramolecular materials; hence, it is imperative to have a timely survey of current developments and trends related to this versatile technique for the design and fabrication of novel materials with desired properties, better handling ability, and scalability to meet the current demand as well as industrial needs. Studies demonstrating the feasibility of micro-/nanocomposite materials design via the EA method for various promising applications are also identified. Prospective outlooks and recommendations for further development of the EA method for advanced composite materials development are also mentioned.

\section{EA Method and LbL Assembly}

\subsection{EA Method and LbL Assembly for Materials Design}

After the initial discovery and concept of LbL film formation through the electrostatic interaction of polyelectrolytes, this concept has been widely used in layered film assembly by the sequential interaction of polycation and polyanion adsorption, as shown in Figure 1. Details on the fundamentals of the EA method and LbL assembly has been thoroughly described by Guzman's group elsewhere $[19,20]$. As indicated in Figure 1, the polycation and polyanion induce positive and negative surface charges on the matter to which they are attached, respectively. By exploiting the charge exhibited by the polyelectrolytes, electrostatic interactions of either repulsion (same charge) or attraction 
(opposite charge) are generated, and this promotes the migration, rearrangement, and assembly of the charged matter.

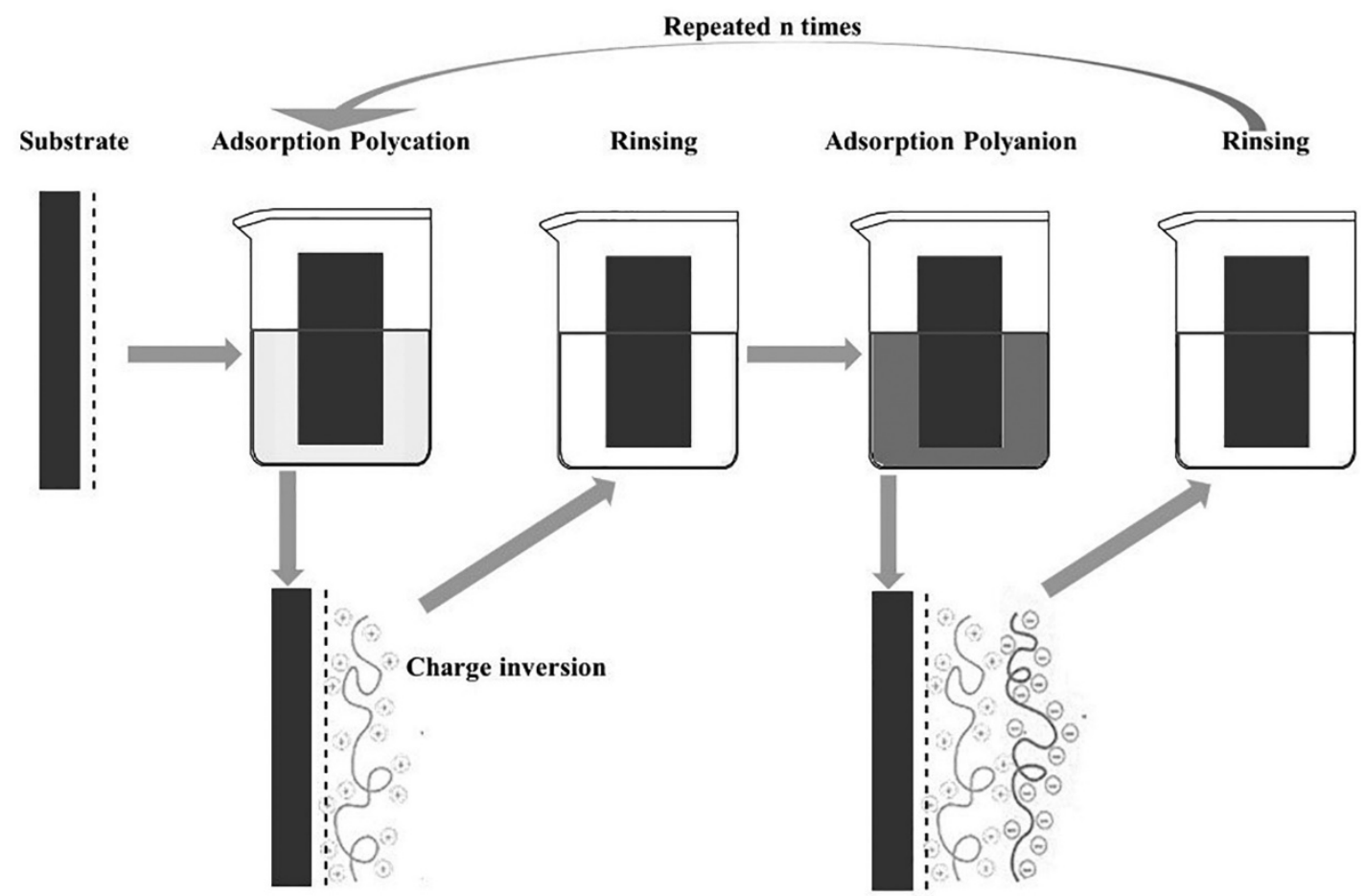

Figure 1. Schematic representing the different steps of polyelectrolyte adsorption used in electrostatic assembly and layer-by-layer (LbL) method. Reprinted with permission from [20], copyright (2020) Elsevier.

The LbL assembly of films achieved by controlling and manipulating the electrostatic charges of a matter using polyelectrolytes has been reported [6,20-25]. As the electrostatic surface charge generation is induced in an aqueous solution, the factor of geometrical limitation hardly applies, allowing the exploration of this method for novel composite materials design using substrates with sophisticated shape. With the rapid development in nanotechnology, the importance of controlled materials design in the micro- and nanoscale has never been more crucial. More importantly, the homogeneity and controlled distribution of materials within a multiscale structure are also crucial factors for advanced functional materials design [1]. This has led to a new concept known as nano-architectonics materials design $[7,23,25,26]$. Studies carried out by Ariga's group have demonstrated the use of the EA and LbL method for various bioscience-related molecular materials design such as multicomponent protein films [24], functional molecules [3], 2D dynamic surfaces [23,27], drug delivery [6,28], controlled thin film assemblies [29], bioactive nanocarbon assemblies [26], controlled supramolecular interfaces, and polymorphism $[7,25]$.

On the other hand, by controlling and exploiting the surface charge of polyelectrolytes on different types of material surfaces, the fabrication of composite materials with a good precision to exhibit controllable properties have also been reported. Muto's group have employed the EA method for various materials design ranging from polymer to ceramics with different structural forms such as fiber, sheets, whisker and foam-structured materials, as shown in Figure 2 [1,8-10,30-35]. 

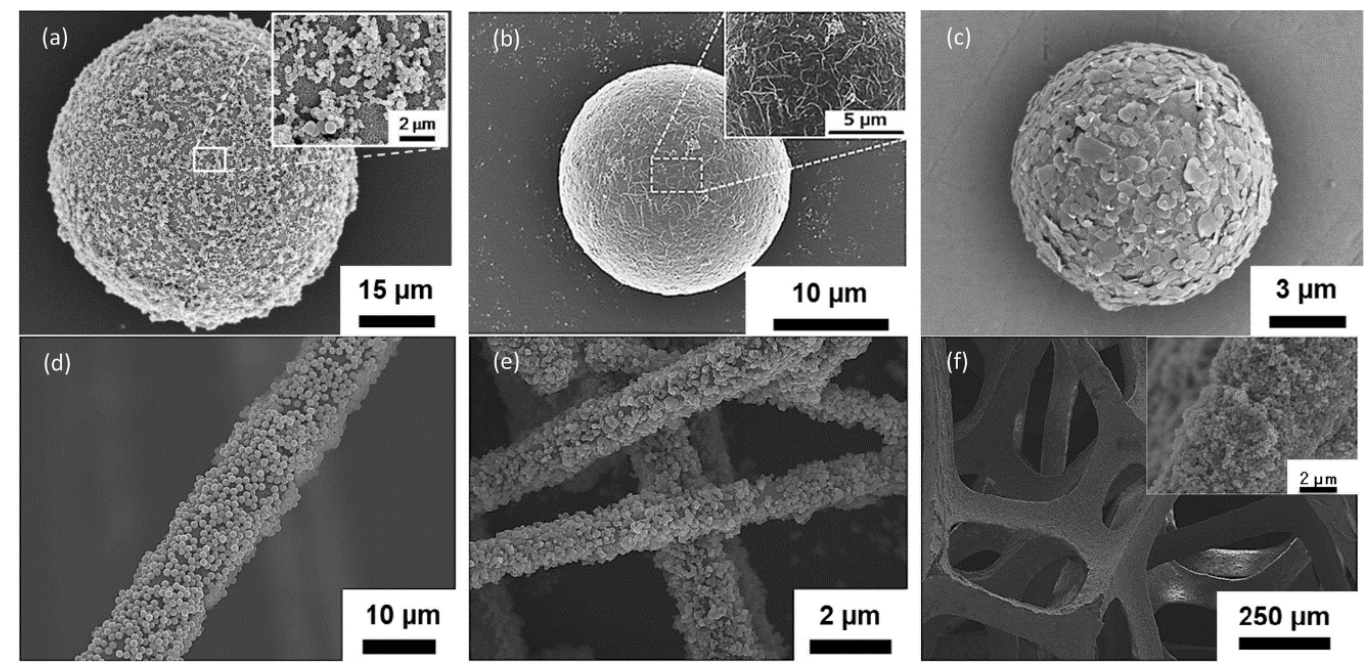

Figure 2. Scanning electron microscope (SEM) images of the nano and micro-assembled composites obtained by the electrostatic assembly (EA) method. (a) Carbon microspheres- $\mathrm{Al}_{2} \mathrm{O}_{3}$, (b) carbon nanotubes- poly (methyl methacrylate) (CNT-PMMA), (c) $\mathrm{BN}-S i O_{2}$, (d) $\mathrm{SiO}_{2}$-carbon fiber, (e) $\mathrm{Al}_{2} \mathrm{O}_{3}$-SiC whisker, and (f) $\mathrm{Al}_{2} \mathrm{O}_{3}$-urethane foam. Reprinted with permission from [1], copyright (2019) Springer.

Generally, the surface charge of starting materials is adjusted by immersing in polyelectrolytes. The deposition of charged polyelectrolytes is driven by the charge inversion phenomenon, where the adsorption of the polyelectrolyte proceeds to the opposite polar charge (until a certain degree) without halting at a neutral charge. This phenomenon, which is also known as overcompensation, enables the alteration and manipulation of a material's surface charge for composite formation as well as an alternate deposition of polyelectrolyte building blocks with improved stability $[1,20]$. As shown in Figure 3, switching of the surface charge with zeta potential from positive to negative and vice versa with an alternate deposition of polyanion (PSS) and polycation (PDDA) on the surface of $\mathrm{Al}_{2} \mathrm{O}_{3}$ granules and carbon nanoparticles was demonstrated prior to the compositing process [30]. The polyelectrolyte adsorption is a stable process that is almost irreversible, due to multiple segment bonding of the polymeric chain to a material's surface. Desorption can only occur with the simultaneous detachment of the bonds from the polyelectrolyte from the material's surface, which is rather impossible [36].

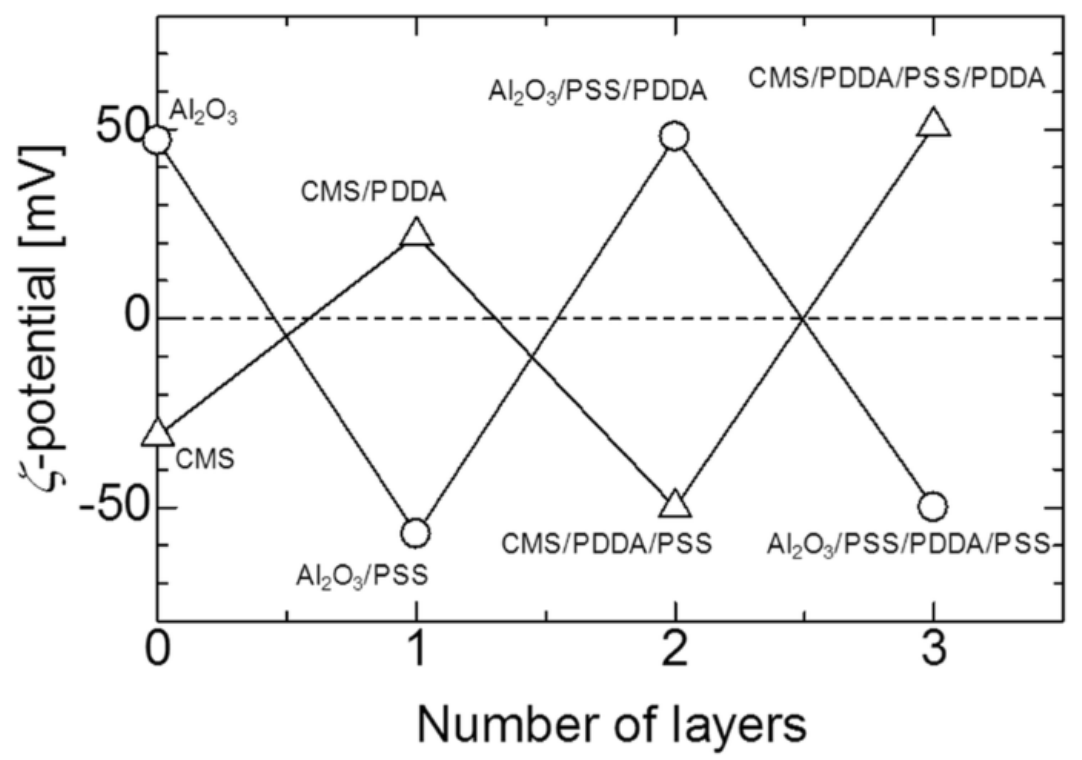

Figure 3. Zeta potential of $\mathrm{Al}_{2} \mathrm{O}_{3}$ granules and carbon nanoparticles with the alternate deposition of polyanion (PSS) and polycation (PDDA). Reprinted with permission from [30], copyright (2019) Springer. 


\subsection{Types of Assemblies and Polyelectrolytes}

Various techniques of film formation utilizing the electrostatic interaction of charged surfaces, via covalent bond, hydrogen bond, molecular recognition, charge transfer interaction, etc. have been reported [20]. The important parameters affecting LbL formation recently reported by Guzman et al. include the materials charge density, concentration, type of solvent, temperature, $\mathrm{pH}$, and polyelectrolyte molecular weights [20]. As in the assembly process itself, attention should also be paid to the surface nature of the materials, assembly time (immersion time), rinsing, and drying process during consecutive layer assembly as well as supporting electrolyte [1,19].

When materials with low surface-charge density are used, the polyelectrolyte adsorption to the limited active groups on the surface will provide a larger number of oppositely charged groups for the subsequent reaction while at the same time increasing the surface exposure [14]. The multiplication of surface functionality can be achieved over a few layers by increasing the surface zeta potential before a constant region is achieved. In the EA method, the generation of functional surfaces for the electrostatic derived assembly is obtained using polyelectrolytes. Controlling the surface-charge strength is also one way to achieve the controlled assembly of materials. The surface charge can be measured using zeta potential. For example, a particle suspension with a zeta potential of $\pm 25 \mathrm{mV}$ or higher indicates a stable suspension. However, this stability analysis does not apply to solid surfaces due to the different physical principles. In addition, zeta potential can provide information about the surface functionality induced by certain chemical groups and interaction of the liquid-on-solid adsorption process.

Many types of polyelectrolytes are used by researchers to control the assembly process using materials at the desired levels (molecular/nano/microlevel) as building blocks. By adjusting the condition where the polyelectrolytes are used, the surface charge as well as the assembly condition can be changed to subsequently alter the final physicochemical properties of the composites obtained [20-22]. Examples of commonly used polyelectrolytes are poly (4-styrenesulfonate of sodium), poly (diallyldimethylammonium chloride), poly (ethylenimine), poly (acrylic acid), poly (allylamine hydrochloride), etc. Natural polyelectrolytes such as chitosan, dextran, amine hyaluronic acid, and heparin are also used for bio-related fields [7].

In the following section, recent applications reported for emerging technologies using the EA method or LbL assembly are described to give an overview of the current trend in the use of the EA method for composite fabrication.

\section{Composite Fabrication via EA Method and their Applications}

\subsection{Formation of Electromechanical or Electrochromic Responsive LbL Composite Films}

Using the EA method in the formation of LbL films, the controlled deposition of films can be achieved. By utilizing the LbL assembled films as a building block, further optimization and coupling via electrochemical methods can be used to fabricate functional nano-devices such as sensors, microelectromechanical systems (MEMS), and electrochromic materials [15]. The strategy is to incorporate electro-responsive materials within the LbL films in the generation of stimuli responsive polymer composite films. For example, in the development of MEMS systems, a transducer that converts electrical energy to mechanical energy is one of the core components. In the development of low-cost MEMS, many researchers are focusing on the development of electroactive polymers because they are inexpensive, possess a wide range of environmental endurance, and have good compatibility with many fabrication techniques. To incorporate redox active materials in the fabrication of electro-responsive materials, electro-swelling/deswelling of LbL films is commonly used. Hence, the assembled LbL films will experience swelling/deswelling during ion exchange due to the redox of the incorporated active materials. The electroactive materials confined or embedded within the electrostatic deposited film exhibited improved electro-responsive properties. One example of the above-mentioned phenomenon is shown in Figure 4, where the redox of ferrocyanide ions within the electrostatic assembled films of polyglutamic acid and poly (allylamine hydrochloride) resulted in the electro-swelling of the LbL 
assembled films. During charge compensation, the diffusion of counter-anions with water molecules occurs causing the swelling and deswelling process, which can be controlled by changing the salts dissolved in the solution [15].
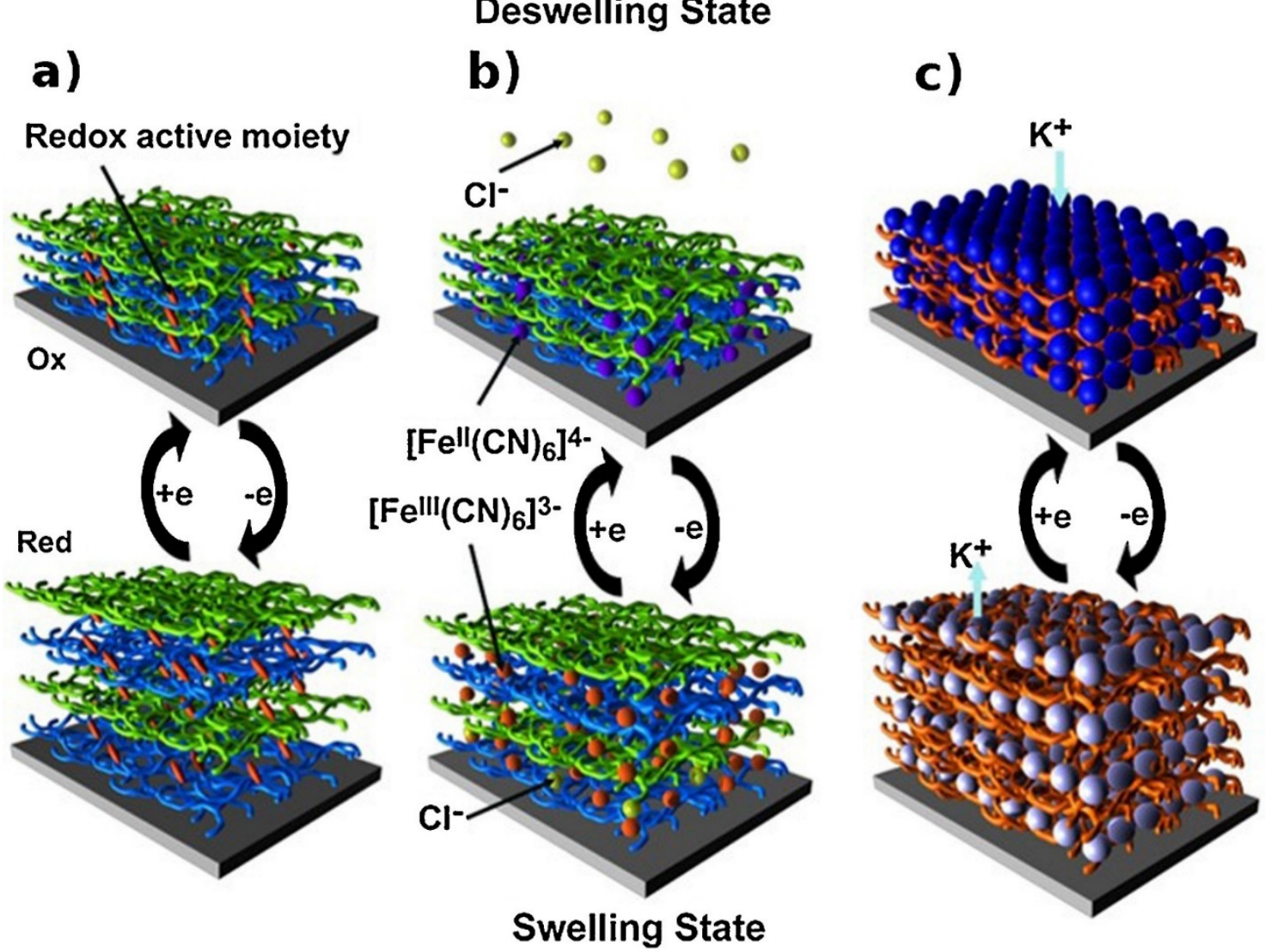

Figure 4. Electro-swelling processes of LbL films. Electro-swelling/deswelling of LbL films based on (a) redox active moieties grafted onto one of the polyelectrolytes, (b) free redox active molecules confined in LbL films, and (c) redox active component-based film. Reprinted with permission from [15], copyright (2015) Elsevier.

In a recent study on the fabrication of a flexible electrochromic display, Qi et al. demonstrated the formation of $2 \mathrm{D}$ composite materials consisting of $\mathrm{V}_{2} \mathrm{O}_{5}$ nanosheets and graphene films using the electrostatic LbL method, as shown in Figure 5a. The composites exhibited an impressive ultrafast response time in coloring and bleaching because of the reduced agglomeration, improved electronic conductivity, and reduced charge transport distance, as shown in Figure 5b [37]. When the endurance of the device was tested by bending at an angle of $90^{\circ}$ for 100 cycles, rapid electrochromic response time was still observed. This shows that the EA method possesses excellent potential for the future development of flexible devices. 


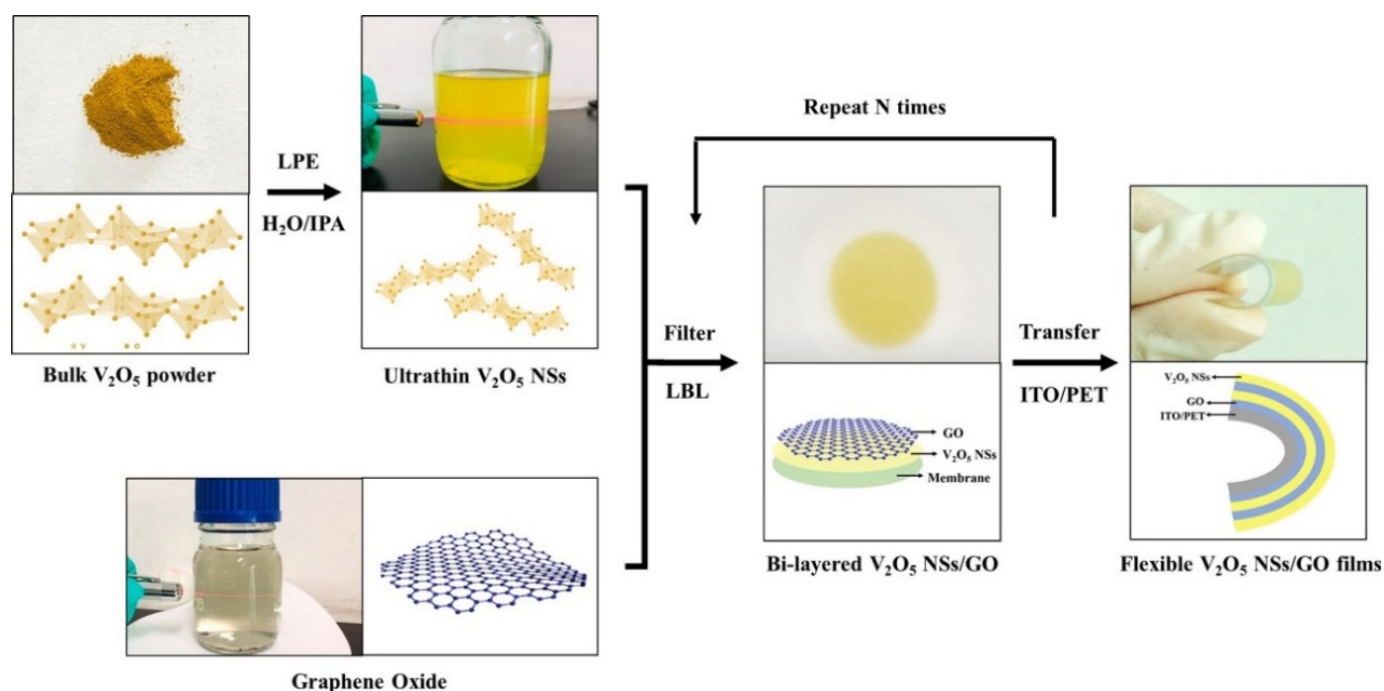

(a)

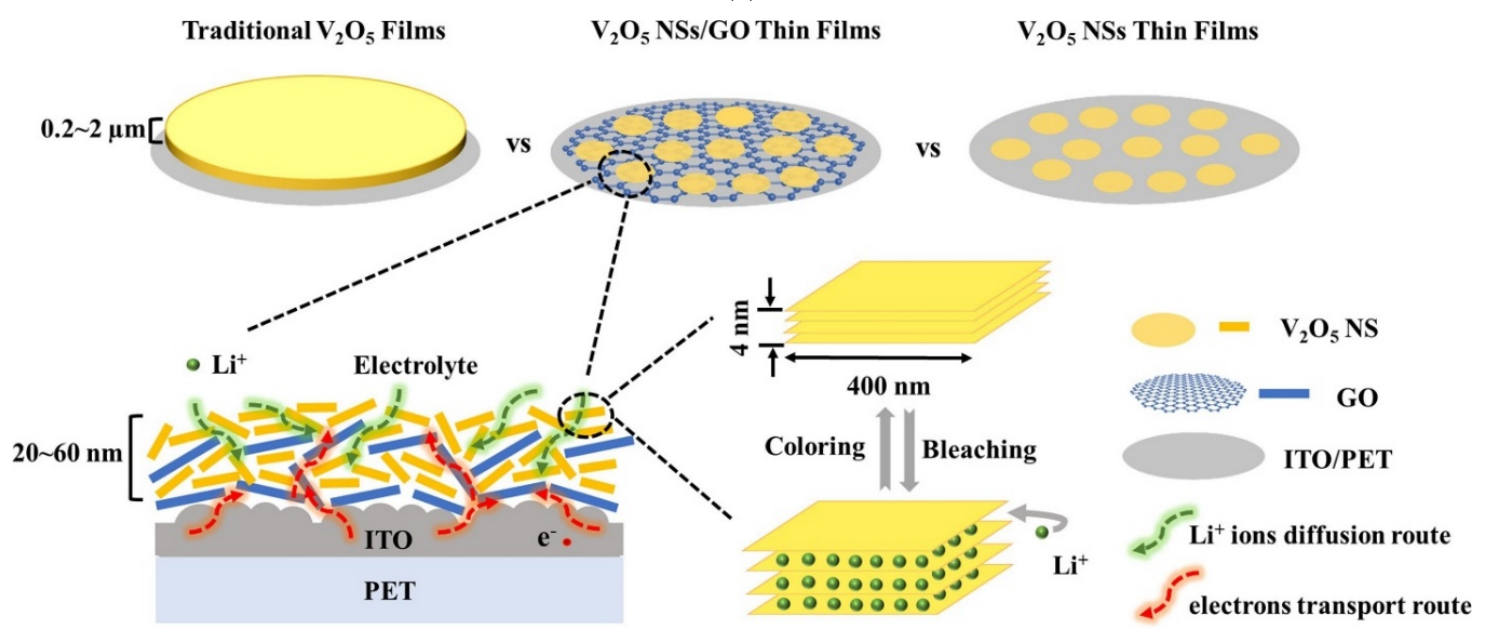

(b)

Figure 5. (a) Schematic illustration of the LbL assembly process of flexible $\mathrm{V}_{2} \mathrm{O}_{5} \mathrm{NSs} / \mathrm{GO} @ \mathrm{ITO} / \mathrm{PET}$ films. (b) Schematic illustration of the coloring and bleaching processes of $\mathrm{V}_{2} \mathrm{O}_{5} \mathrm{NSs} / \mathrm{GO}$ films. Reprinted with permission from [37], copyright (2020) Elsevier.

\subsection{Composite LbL Films for Biomedicine and Biomimetic Extracellular Matrix}

In the early stage of LbL development, most studies focused on the use of synthetic polyelectrolytes. However, when considering the application of EA and LbL techniques for biomedical and biomaterials applications, researchers began to focus on the use of natural polyelectrolytes such as chitosan, dextran, amine hyaluronic acid, heparin, etc. [6]. The use of natural polyelectrolytes in LbL assembly provides a new potential for the development of advance structural composites with precise design such as core-shells for drug delivery. Furthermore, the flexibility of post-treatment after LbL assembly is an added advantage, especially for altering the physicochemical properties of the assembled composite films. Parameters such as temperature, light irradiation, electric field induction, $\mathrm{pH}$ adjustment, and vibrational stimulation can be used to adjust the properties.

For the functionalization of biomaterials, it is important to create a microenvironment that mimics the extracellular matrix [17]. By designing polymeric LbL films, current progress has enabled the development from only mimicking cell configuration to the possible control of cell behaviors [16]. The possibilities of biochemical engineering via the EA method is vital for the advancement in biomaterials and tissue engineering fields [17]. Due to the good stability of electrostatically assembled 
films in aqueous solution and its dynamic potential, the microenvironment generated, which is almost equivalent to the natural cellular matrix, is crucial due to the cells' selective recognition to certain biochemical and biophysical conditions. Liu et al. have demonstrated protein immobilization through matrix binding via the LbL technique. As shown in the schematic in Figure 6, the immobilization of a chemoattractant known for hematopoietic stem cell homing and cancer progression called stromal cell-derived factor-1 (SDF-1 $\alpha$ ) was achieved using poly(l-lysine) (PLL) and hyaluronan (HA) polyelectrolytes using the LbL process. This resulted in a significant increase in human epithelial breast cancer cell spreading in the matrix-bound SDF- $1 \alpha$. From their investigation, they found that the cell adhesion on films with matrix-bound SDF- $1 \alpha$ exhibited an obvious spatial organization with good focal adhesion compared to the cells presented with a soluble cue [38]. Their study showed that LbL films were effective as a biomimetic tumoral niche in revealing potent cellular effects as well as underlying mechanisms that can be useful for the research in regenerative therapies against cancer cells such as breast cancer.

A

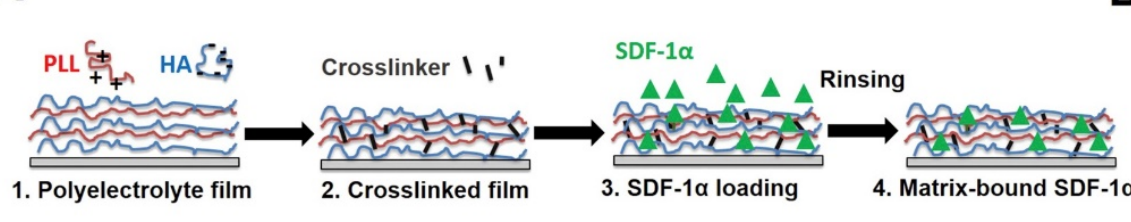

B

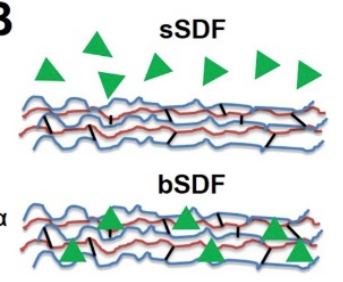

Figure 6. (A) Successive steps for the preparation of matrix-bound stromal cell-derived factor-1 (SDF-1 $\alpha$ ) using layer-by-layer films as extra-cellular matrix with poly(l-lysine) (PLL) and hyaluronan (HA) as polyelectrolytes. The film is first deposited step-by-step (1), then cross-linked (2) and finally loaded with SDF- $1 \alpha$ in acidic conditions $(1 \mathrm{mM} \mathrm{HCl})(3)$, followed by a rinsing step in order to obtain matrix-bound SDF-1 $\alpha$ (4). (B) SDF-1 $\alpha$ can be presented as a soluble cue (SSDF) or in a matrix-bound manner (bSDF). Reprinted with permission from [38], copyright (2017) Elsevier.

\subsection{Composite Materials for Energy Storage and Conversion Technologies}

Recent development in the Internet of Things and electric vehicles has resulted in a demand surge for composite materials with high storage and energy capacity. Electrochemical energy storage systems such as lithium-ion batteries, lithium-sulfur, and metal-air batteries have attracted attention due to their high specific energy capacity $[8,39,40]$. In a recent study carried out on all-solid-state lithium-sulfur batteries, Phuc et al. reported the use of the EA method in the design of their solid electrolyte consisting of $0.67 \mathrm{Li}_{3} \mathrm{PS}_{4}-0.33 \mathrm{LiI}$ (LPSI) and sulfur-carbon nanofiber (S-CNF) using a novel liquid phase route [40]. The schematic for the preparation of the S-CNF via the EA method is shown in Figure 7a-c, while Figure 7d shows the SEM image and energy-dispersive X-ray (EDX) mapping of the S-CNF-LPSI composite. The proper distribution of S-CNF within the LPSI promoted an electrically conductive pathway to overcome the $\mathrm{Li}_{x} \mathrm{~S}_{\mathrm{y}}$ electronic insulation behavior, enabling a good lithium-sulfur battery performance. In the development of $\mathrm{Fe}$-air batteries, Tan et al. reported a facile and simple way to decorate iron oxide particles $\left(\mathrm{Fe}_{3} \mathrm{O}_{4}\right)$ at room temperature on carbon paper in a short period of 10 min using the EA method. The $\mathrm{Fe}_{3} \mathrm{O}_{4}$-decorated carbon paper was used in the evaluation of alkaline aqueous and all-solid-state Fe-air batteries with a maximum discharge capacity of 460 and $70 \mathrm{mAh} \mathrm{g}^{-1}$, respectively [41]. 

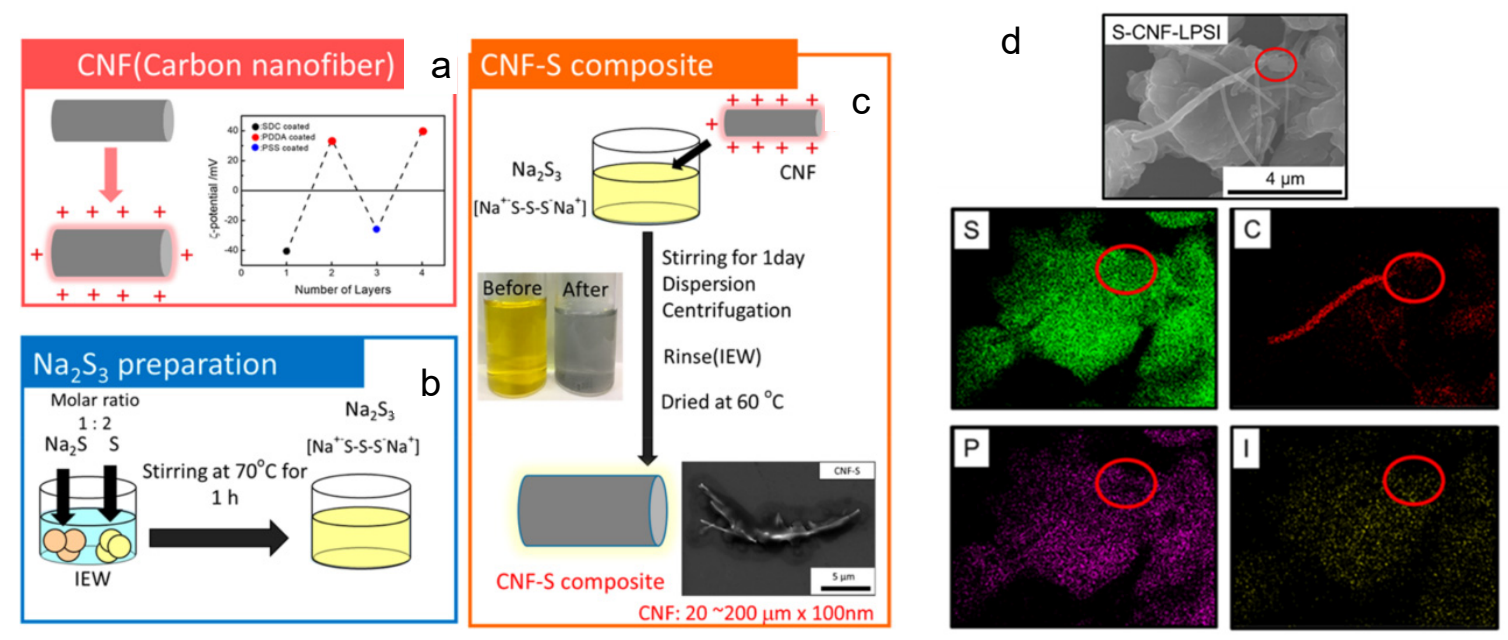

Figure 7. Schematics of sulfur-carbon nanofiber (S-CNF) composite preparation: (a) adjustment of the CNF surface charge, (b) formation of $\mathrm{Na}_{2} \mathrm{~S}_{3}$ solution, (c) S-CNF composite formation. The SEM image and and energy-dispersive X-ray (EDX) mapping results for S, C, P, and I of the S-CNF-LPSI $\left(\mathrm{Li}_{3} \mathrm{PS}_{4}-0.33 \mathrm{LiI}\right)$ composite are shown in (d). Reprinted with permission from [40], copyright (2020) ACS.

As 2D graphene-derived materials are becoming an integral part of the materials used in the development of advanced functional composites, they have been incorporated in various composites for a wide range of applications [42]. The application of the EA method for the integration of graphene materials into composites has been reported in the literature. For supercapacitor applications, Fenoy et al. reported on the fabrication of electrode materials using electrostatic assembled polyaniline-PSS complex layer with iron oxide nanoparticles decorated graphene layers in aqueous solution [11]. They demonstrated an excellent electrochemical capacitance of 768.6 and $659.2 \mathrm{~F} \mathrm{~g}^{-1}$ in $0.1 \mathrm{M} \mathrm{HCl}$ and $0.1 \mathrm{M} \mathrm{KCl}\left(\right.$ at $1 \mathrm{~A} \mathrm{~g}^{-1}$ ), respectively with high cycling stability up to 1600 cycles. In another interesting development, a possible diffusion-driven mechanism of LbL assembled layers was reported by Hong et al. They demonstrated the formation of a porous reduced graphene oxide ( $\mathrm{rGO}$ )/polyaniline (PANI) composite as the binder-less electrode for supercapacitors [43]. The strong electrostatic interaction between graphene oxide (GO) and the branched polyethyleneimine after the diffusion process enabled the formation of a porous foam-like structure as a template for the polymerization of PANI, as shown in Figure 8. This simple fabrication of a binder-less electrode yielded a capacitance performance of $438.8 \mathrm{~F} \mathrm{~g}^{-1}$ at $0.5 \mathrm{~A} \mathrm{~g}^{-1}$ in $1 \mathrm{M} \mathrm{H}_{2} \mathrm{SO}_{4}$.

For fuel cell applications, proton exchange membrane fuel cell (PEMFC), which possesses a high energy conversion efficiency and low-cost fabrication, is an alternative source for a clean energy [44]. Currently, researchers are working on the development of PEMFC due to its higher reaction kinetics and easier heat management. Current challenges include obtaining a polyelectrolyte membrane (PEM) that exhibits good proton conduction at elevated temperature and low humidity [45]. In order to obtain a higher phosphoric acid uptake to promote higher proton conductivity, the formation of organic-inorganic hybrid membranes to improve the physico- and electrochemical properties of the PEM were reported [46-48]. Using the EA assembly, controlled multilayer LbL membrane formation enabled the fabrication of PEM with desired properties such as improved proton conductivity and mechanical property $[45,49]$. Che et al. reported the formation of multilayer-component PEM using sulfonated polyetheretherketone (SPEEK) as a polyanion while polyurethane (PU) and the ionic liquid of 1-butyl-3-methylimidazolium were used as a polycation, as shown in Figure 9. The films obtained as shown in Figure 9 had a thickness of approximately $25 \mu \mathrm{m}$ after 100 layers of coating, and the films exhibited satisfactory mechanical strength and excellent conductivities with different phosphoric acid doping levels [45]. 


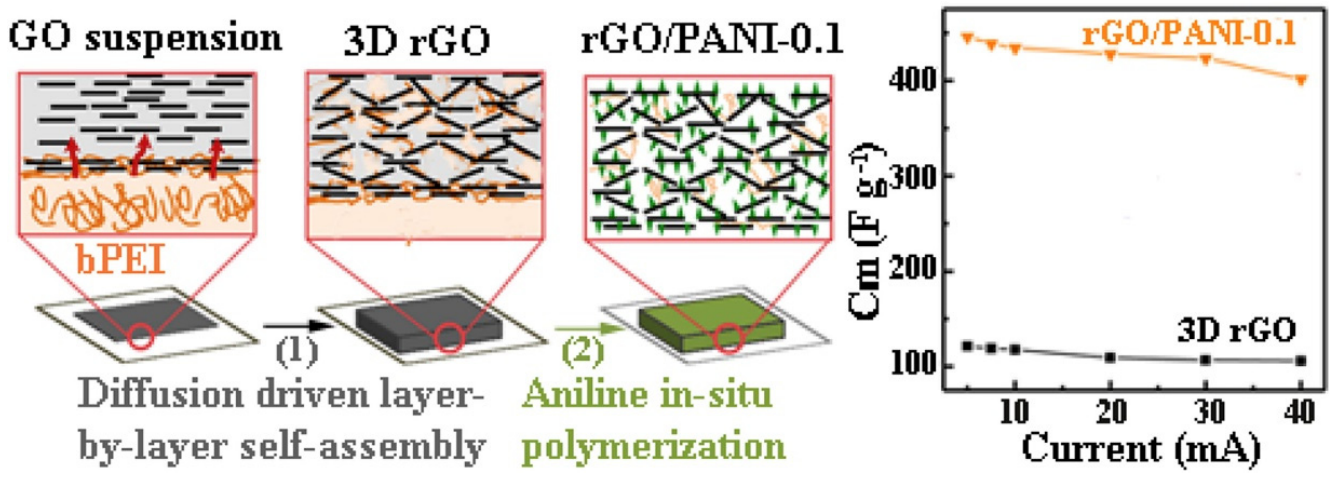

Figure 8. Schematics of preparing reduced graphene oxide (rGO)/PANI (polyaniline) composite film. Branched polyethyleneimine (bPEI) solution was coated on a filter paper. The coated paper was immersed in assembly graphene oxide (GO) suspension. GO and bPEI formed a stable complex layer at first. Then, bPEI diffused out of the reservoir and complexed with GO sheets. This complexation and diffusion process continued, eventually developing into a thicker GO/bPEI composite film. Some square GO/bPEI films $\left(2 \times 2 \mathrm{~cm}^{2}\right)$ were cut and detached from the substrate, then subjected to a hydrothermal treatment at $190{ }^{\circ} \mathrm{C}$. Finally, the hydrothermally reduced-GO films were used as a template for the polymerization of aniline. The $\mathrm{rGO} / \mathrm{PANI}$ exhibits capacitance of $438.8 \mathrm{~F} \mathrm{~g}^{-1}$ at $0.5 \mathrm{~A} \mathrm{~g}^{-1}$ in $1 \mathrm{M} \mathrm{H}_{2} \mathrm{SO}_{4}$. Reprinted with permission from [43], copyright (2017) Elsevier.
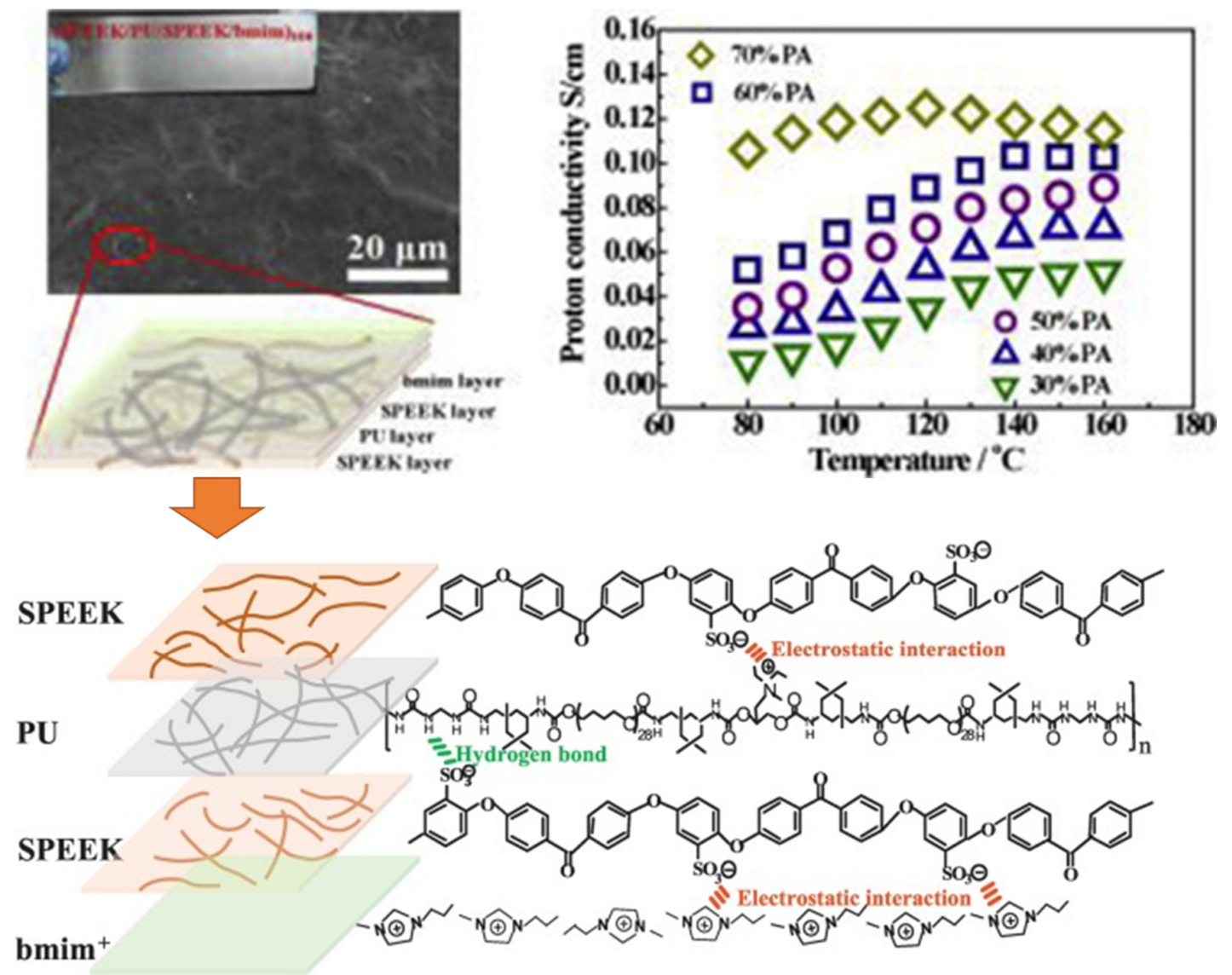

Figure 9. Multi-component membrane of SPEEK-PU-SPEEk-bmim obtained via the LbL method, which demonstrated a maximum proton conductivity of $1.03 \times 10^{-1} \mathrm{~S} / \mathrm{cm}$. Schematic of the interaction force between SPEEK and PU, SPEEK and $\mathrm{bmim}^{+}$in one layer of the LbL membrane. Reprinted with permission from [45], copyright (2019) Elsevier. PU: polyurethane, SPEEK: sulfonated polyetheretherketone, bmim: 1-butyl-3-methylimidazolium. 


\subsection{Composite Materials for Additive Manufacturing}

Additive manufacturing (AM) technology is regarded as the next-generation manufacturing revolution that would enable the rapid and moldless formation of complicated components [50-54]. The potential of AM is massive for the production of functional composites from a wide range of materials such as metals, polymers, and ceramics. AM enables the rapid prototyping and transformation of product manufacturing with precise customization. The synchronization of computer-aided design with AM has enabled the formation of complex 3D structures within a short time with maximum material utilization while enabling flexible customization and design. According to Tofail et al., AM is close to being a "bottom-up" manufacturing process, where the desired structure is fabricated using a "layer-by-layer" approach, resulting in unprecedented freedom in the manufacturing processes [52]. In AM 3D printing technology, the ability to sinter the materials via indirect and direct laser sintering of the printed artifact is one important factor for rapid prototyping. Although breakthroughs have been reported for metal and polymeric materials, laser sintering of ceramics remains a challenge due to their high melting point, poor thermal shock resistance, poor ductility, and limited laser absorptivity $[55,56]$. In the work reported by Kuwana et al., cellulose nanofiber (CNF) decorated alumina $\left(\mathrm{Al}_{2} \mathrm{O}_{3}\right)$ powders obtained via EA were used as a composite for the selective laser sintering of $\mathrm{Al}_{2} \mathrm{O}_{3}$ [32]. The EA method enabled the homogeneous adsorption of $\mathrm{CNF}$ onto $\mathrm{Al}_{2} \mathrm{O}_{3}$ particles, which were converted to carbon residue after the heat treatment to allow improved laser absorption for the sintering process. The feasibility of using naturally abundant CNF in materials design also promotes sustainability for AM. In another recent work, Yavari et al. studied additive manufactured bio-functionalized meta-biomaterial composites with infection prevention and bone tissue regenerative properties [57]. The LbL coating was carried out using gelatin- and chitosan-based coatings containing either bone morphogenetic protein (BMP)-2 or vancomycin on the surface of selective laser melted porous structures made from commercial pure titanium, as shown in Figure 10. This study unequivocally demonstrates that multifunctional additive manufactured composite materials can be fabricated using the EA method.

a
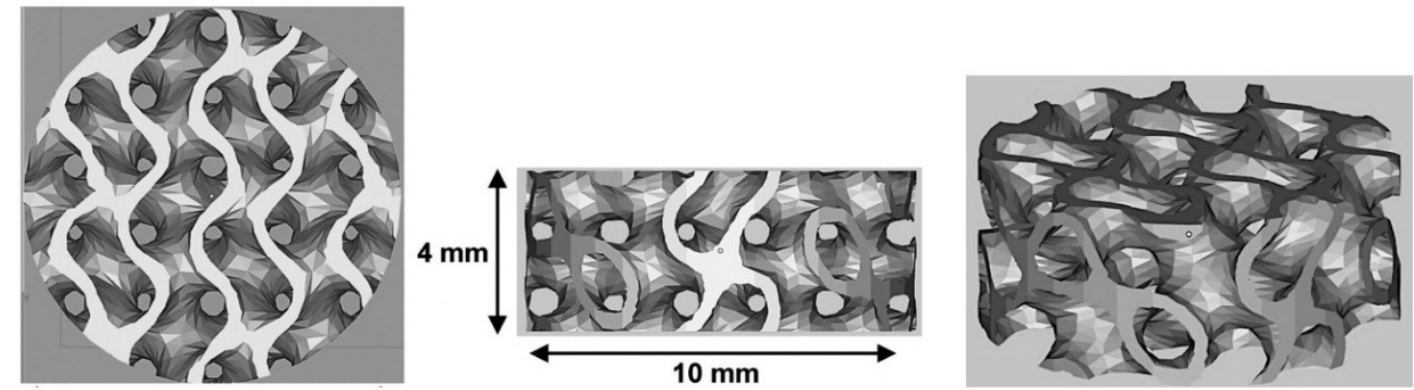

b

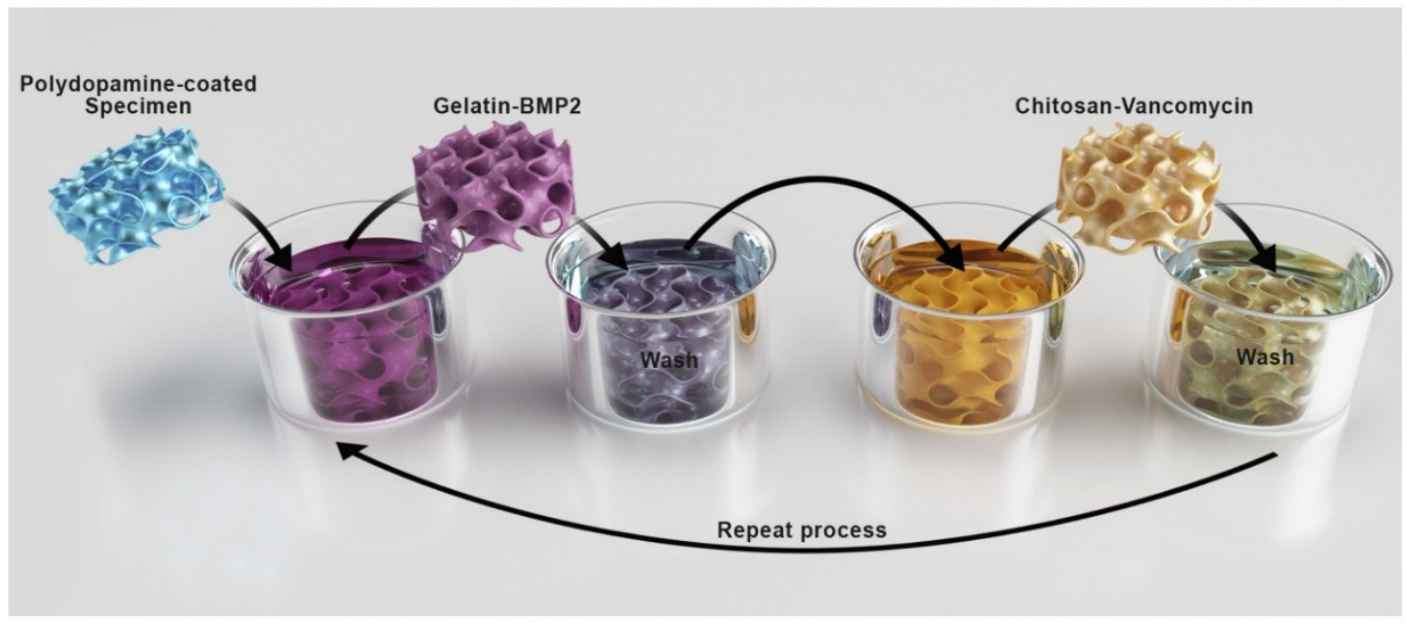

Figure 10. Cont. 

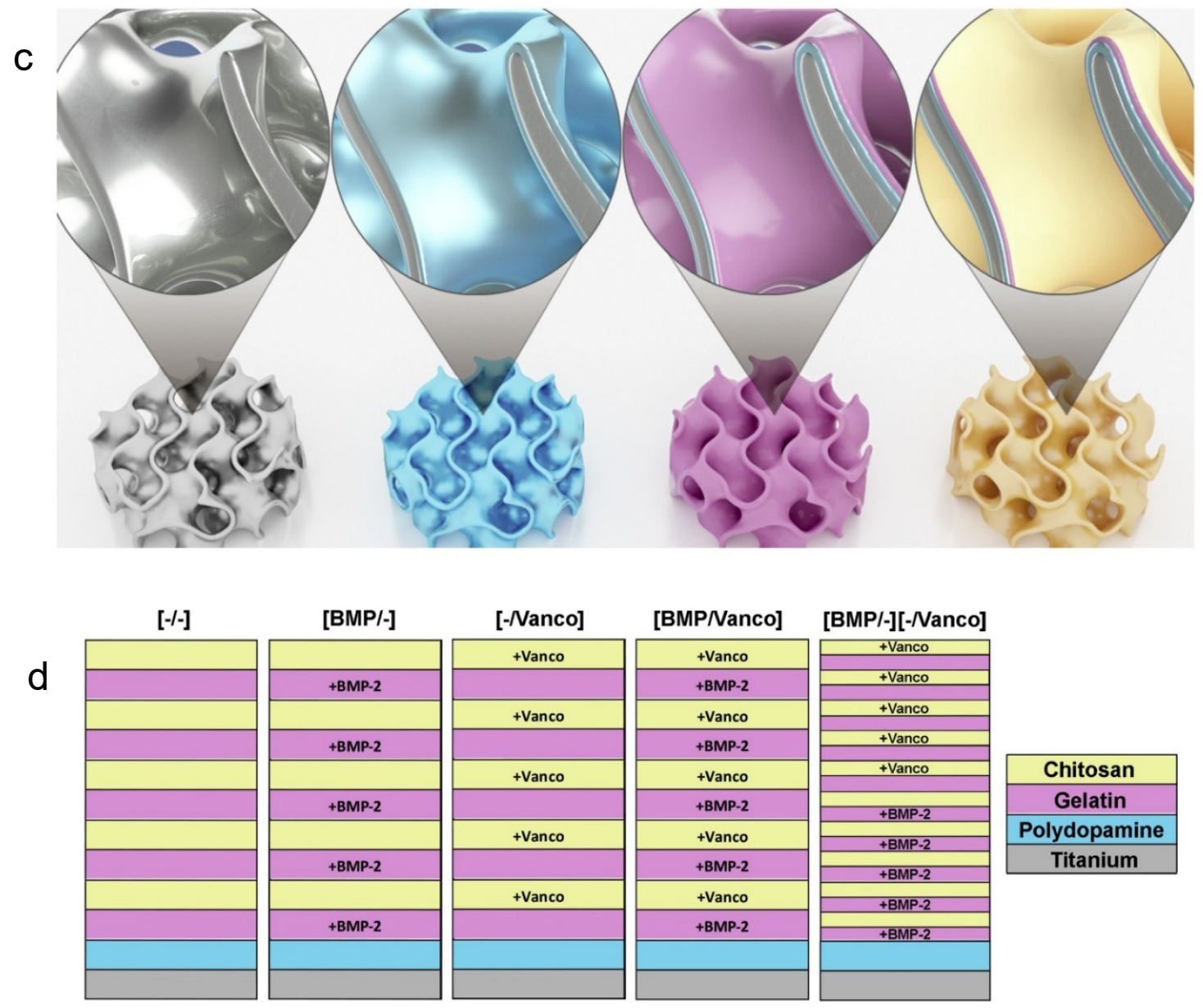

Figure 10. Computer-aided design drawings of the porous structured titanium used as input for the AM process (a). Schematic illustration of the layer-by-layer coating process $(\mathbf{b}, \mathbf{c})$ and the resulting surface layers (d). Reprinted with permission from [57], copyright (2020) Elsevier.

\subsection{Ceramic Composites}

\subsubsection{Mechanical Properties Control of Carbon-Based $\mathrm{Al}_{2} \mathrm{O}_{3}$ Composites}

Carbon-based $\mathrm{Al}_{2} \mathrm{O}_{3}$ composites have attracted attention due to their exceptional mechanical properties such as failure strength, toughness, and wear resistance [58]. In addition, other properties such as the electrical and thermal properties of these composites can also be altered [59-61]. By using the EA method to control the decoration of carbon additives on $\mathrm{Al}_{2} \mathrm{O}_{3}$, the mechanical properties of carbon-ceramic composites can be achieved. In a recent study that used microparticles of $\mathrm{Al}_{2} \mathrm{O}_{3}$ granules with adsorbed carbon nanoparticles (CNP) on their surface, Tan et al. demonstrated that by controlling the amount of $\mathrm{CNP}$ additives and $\mathrm{Al}_{2} \mathrm{O}_{3}$ microparticle size, different surface coverage could be obtained. This led to a controlled microstructure formation with controllable mechanical properties. The good homogeneity of $\mathrm{CNP}$ decorated on $\mathrm{Al}_{2} \mathrm{O}_{3}$ particles played an important role in the formation of an interconnected carbon layer along the $\mathrm{Al}_{2} \mathrm{O}_{3}$ boundaries influencing the final mechanical properties, as shown in Figure 11 [30]. The controlled amount of CNP decoration at the grain boundaries influenced the hardness of the composites, which was determined by an indentation test. 

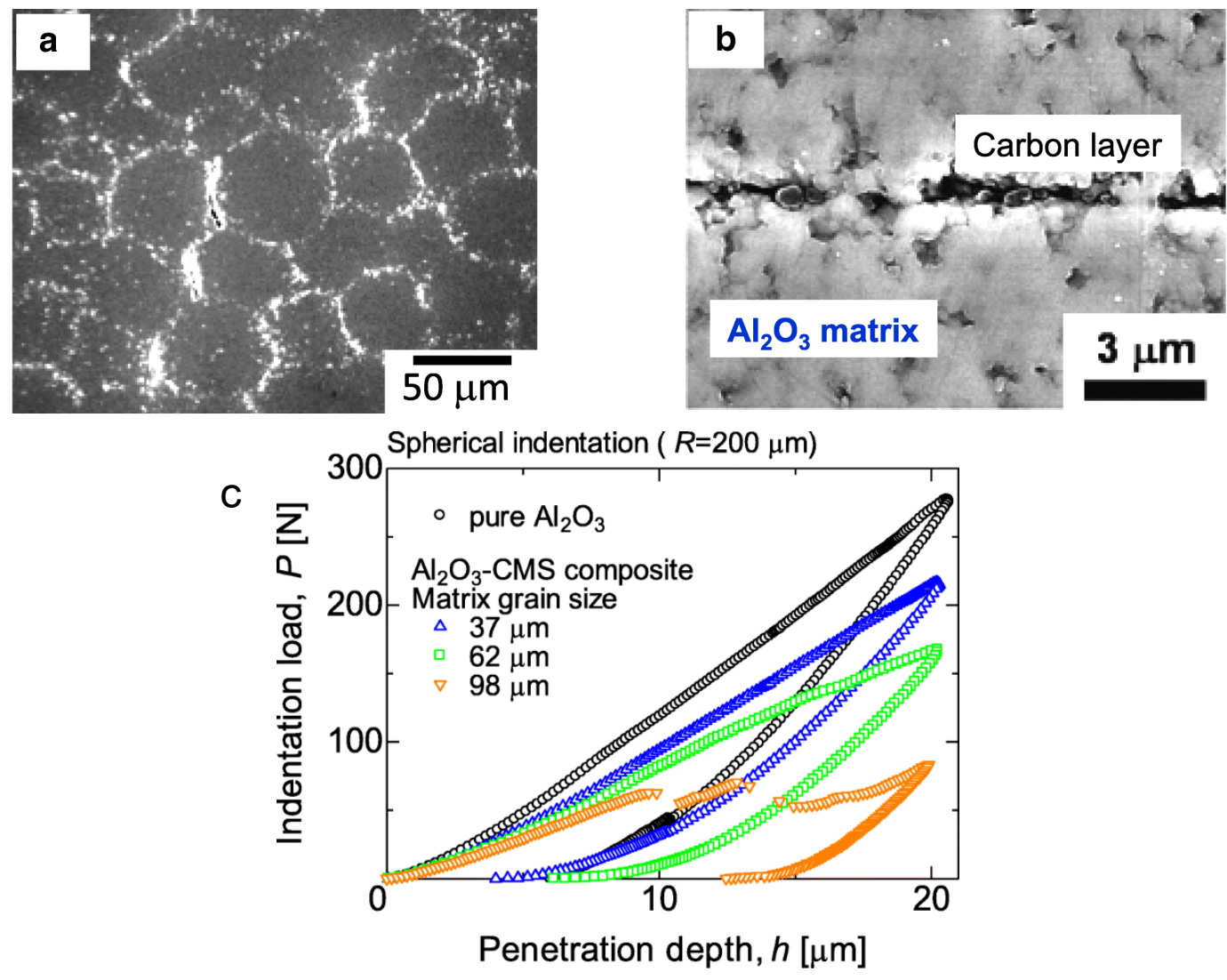

Figure 11. (a) Microstructure of $0.6 \mathrm{vol} \%$ carbon nanoparticles (CNP) $-\mathrm{Al}_{2} \mathrm{O}_{3}$ composite using $\mathrm{Al}_{2} \mathrm{O}_{3}$ with the average diameter of $62 \mu \mathrm{m}$. (b) Grain boundary of $\mathrm{CNP}-\mathrm{Al}_{2} \mathrm{O}_{3}$ composite. A carbon layer could be observed at the interface between the $\mathrm{Al}_{2} \mathrm{O}_{3}$ matrix. (c) Hysteresis curves of indentation load and penetration depth of $1.0 \mathrm{vol} \% \mathrm{CNP}-\mathrm{Al}_{2} \mathrm{O}_{3}$ composites. Reprinted with permission from [30], copyright (2019) Springer Open.

\subsubsection{Porous Ceramic Composites}

Porous ceramic materials with controllable microstructures possess a good potential for applications such as heat insulation, sound dampening, bio-ceramics, and as catalyst carriers for lightweight structural components $[55,62,63]$. In the fabrication of porous ceramic materials, various methods such as sol-gel, freeze-casting, the addition of a pore-forming agent, and partial sintering methods are employed $[64,65]$. However, the achievement of a controlled homogenous distribution of the porous structure remains a challenge, especially when more than one elemental material is used in the composite mixture. The use of the EA method to control the formation of a porous ceramic material consisting of $\mathrm{Al}_{2} \mathrm{O}_{3}$ and silica $\left(\mathrm{SiO}_{2}\right)$ without the use of pore-forming agents has been recently reported [10]. By changing the volume percent of $\mathrm{SiO}_{2}$ particles addition, which affects the coverage percentage of $\mathrm{SiO}_{2}$ on the surface of $\mathrm{Al}_{2} \mathrm{O}_{3}$, the control of microstructure formation, open porosity, as well as the mechanical properties of the sintered $\mathrm{Al}_{2} \mathrm{O}_{3}-\mathrm{SiO}_{2}$ composite ceramics were demonstrated.

\subsubsection{Translucent Ceramic Composite Films with Controllable Optical Properties}

In ceramic film formation, thermal spraying and chemical vapor deposition are commonly used. Due to limitations such as expensive equipment and the thermal stability of substrates, researchers have opted for a more rapid and low-temperature ceramic film fabrication method [66,67]. The feasible formation of compact ceramic films by aerosol deposition (AD) was discovered by Akedo, and since then, this method has been used for various types of ceramic film fabrication [58,67-71]. The advantages 
of the AD method are the rapid ceramic film formation rate and the feasibility of room temperature impact consolidation (without heat treatment) $[66,67,72,73]$. To deposit composite ceramic films with good transparency and desired optical properties, a homogeneous mixture of starting materials is indispensable. Therefore, electrostatic assembled composite powder can be used to obtain the desired optical properties of aerosol-deposited ceramic films [31]. With a homogeneous decoration of indium tin oxide (ITO) or cerium oxide $\left(\mathrm{CeO}_{2}\right)$ nanoparticles on $\mathrm{Al}_{2} \mathrm{O}_{3}$ as shown in Figure 12, tailoring of the ultraviolet and infrared light adsorption properties of transparent $\mathrm{Al}_{2} \mathrm{O}_{3}$ composite films have been recently reported [31]. As shown in the schematics in Figure 12, inhomogeneous powder mixtures with agglomeration will affect the film deposition uniformity, thereby causing the property deterioration of the AD films as compared to electrostatically assembled composite powders.
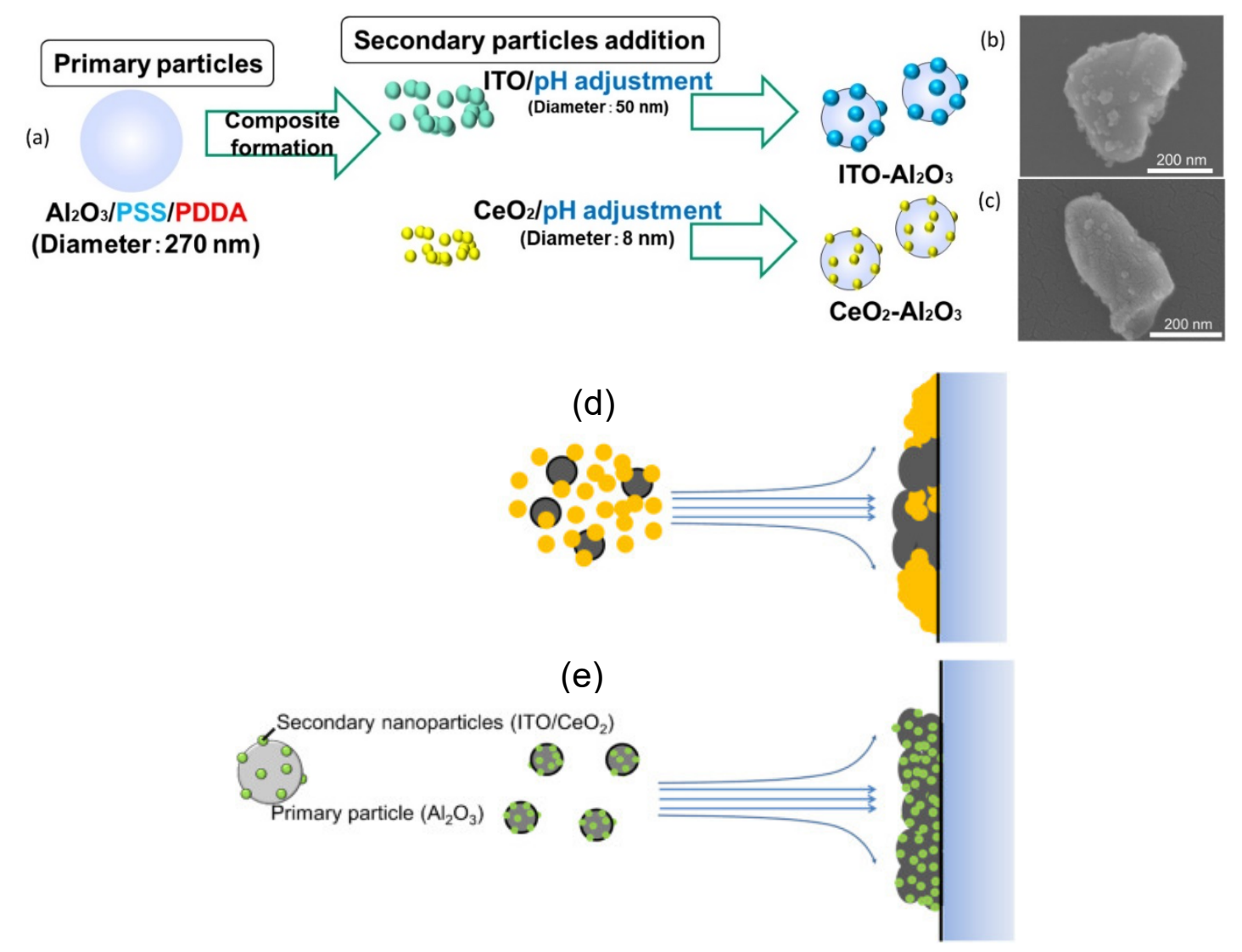

Figure 12. (a) Schematics of the ITO- $\mathrm{Al}_{2} \mathrm{O}_{3}$ and $\mathrm{CeO}_{2}-\mathrm{Al}_{2} \mathrm{O}_{3}$ nanocomposite formation via an electrostatic adsorption method while $(\mathbf{b}, \mathbf{c})$ are the SEM images of the as-obtained ITO- $\mathrm{Al}_{2} \mathrm{O}_{3}$ and $\mathrm{CeO}_{2}-\mathrm{Al}_{2} \mathrm{O}_{3}$ nanocomposites, respectively. The schematic of aerosol-deposited films using (d) mixed oxide nanoparticles and (e) homogenous electrostatically adsorbed nanocomposite oxide particles. Reprinted with permission from [31], copyright (2019) Elsevier.

\subsection{Controlled Properties of Poly (Methyl Methacrylate) (PMMA) Composites}

In the design of lightweight and portable devices, advanced polymer composites with desired properties such as good heat conduction, electrical conductivity, and controlled optical properties are indispensable. The fabrication of high-performance polymer composites by controlling the homogeneity and distribution of the organic and inorganic material composition is one of the important factors for achieving desired properties without compromising the mechanical properties [33,35]. Among the polymeric matrix materials available, poly (methyl methacrylate) (PMMA) is a well-known material due to its good optical clarity, mechanical strength, and thermal stability; they are said to possess the potential to replace glass in various applications $[9,74]$. By using the EA method, the homogenous distribution of functional materials within the PMMA matrix has been reported to enable the generation 
of desired and unique properties in PMMA matrix composites [8,35,75-77]. In a recent study, Yokoi et al. demonstrated the controllability of the thermal conductivity of hexagonal boron nitride (hBN)/PMMA composites by either adjusting the sizes of the hBN sheets or the particle size of PMMA particles used in the EA process [8]. Interestingly, the controlled decoration of hBN sheets within the PMMA matrix led to either the percolation of $\mathrm{hBN}$ or a layer-oriented microstructure demonstrating the different heat conduction behaviors, as shown in Figure 13. On the other hand, in a different application of infra-red (IR) filtering, Tan et al. reported the homogeneous decoration of nano-sized ITO particles within the PMMA matrix in the fabrication of IR filtering PMMA-ITO composite pellets [9]. Precise control of the amount and decoration of ITO within the PMMA matrix is a crucial factor in maintaining the visible light transmission within the composite [78,79]. A good distribution of ITO nanoparticles within the matrix would generate a 3D-ITO framework creating plasmonic responses as well as electric field coupling that results in the IR ray reflectivity for filtering effect generation [80-82].

\section{Spherical particle size}

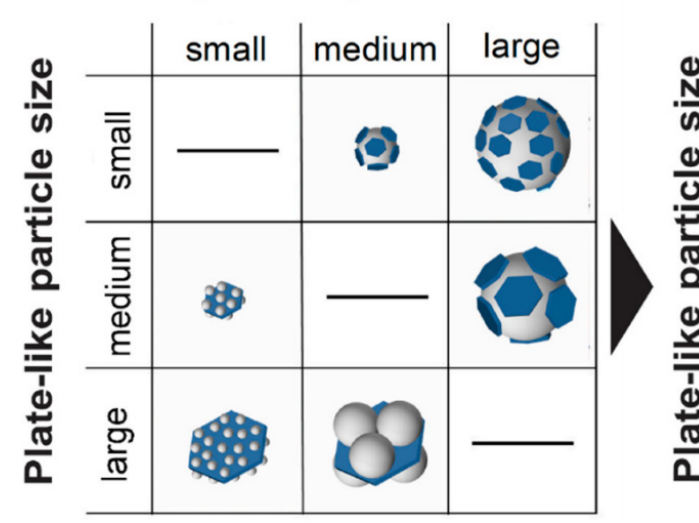

\section{Spherical particle size}

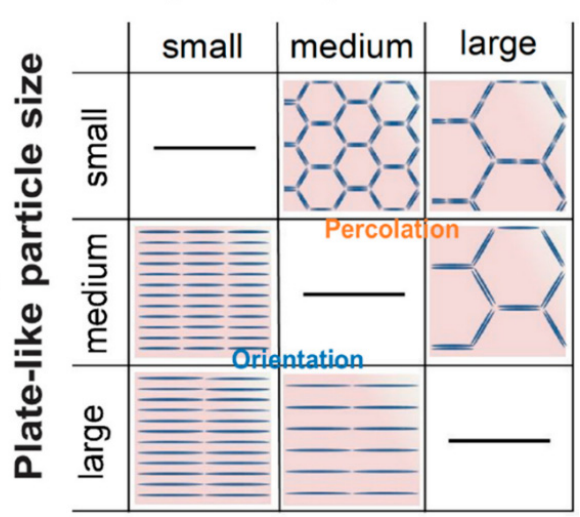

(A)

\begin{tabular}{|l|c|c|c|c|c|}
\hline \multicolumn{1}{|c|}{ Time (s) } & $\mathbf{1}$ & $\mathbf{5}$ & $\mathbf{8}$ & $\mathbf{1 2}$ & $\mathbf{1 6}$ \\
\hline \multirow{2}{*}{\begin{tabular}{l} 
(a) PMMA \\
\cline { 2 - 6 }
\end{tabular}} & $\mathrm{T}: 26.1^{\circ} \mathrm{C}$ & $\mathrm{T}: 32.9^{\circ} \mathrm{C}$ & $\mathrm{T}: 45.1^{\circ} \mathrm{C}$ & $\mathrm{T}: 55.7^{\circ} \mathrm{C}$ & $\mathrm{T}: 62.6^{\circ} \mathrm{C}$ \\
\hline & & & & & \\
\hline $\begin{array}{l}\text { (b) PMMA(0.3 } \\
\mu \mathrm{m})-\mathrm{h}-\mathrm{BN}(18 \\
\mu \mathrm{m})\end{array}$ & $\mathrm{T}: 33.1^{\circ} \mathrm{C}$ & $\mathrm{T}: 60.0^{\circ} \mathrm{C}$ & $\mathrm{T}: 73.2^{\circ} \mathrm{C}$ & $\mathrm{T}: 79.9{ }^{\circ} \mathrm{C}$ & $\mathrm{T}: 83.3^{\circ} \mathrm{C}$ \\
\hline & & & & & \\
\hline
\end{tabular}

(B)

Figure 13. (A) Schematic illustrations showing the composite morphologies of hexagonal boron nitride (hBN)/poly (methyl methacrylate) (hBN/PMMA) and PMMA/hBN composite particles with the corresponding microstructures obtained. (B) Thermograph images of (a) PMMA, (b) PMMA $(0.3 \mu \mathrm{m}) / \mathrm{hBN}(18 \mu \mathrm{m})$, and $(\mathrm{c}) \mathrm{hBN}(5 \mu \mathrm{m}) / \operatorname{PMMA}(12 \mu \mathrm{m})$ composite pellets after infrared thermography irradiation. Reprinted with permission from [8], copyright (2020) MDPI. 


\section{Prospective Outlooks}

Despite the vast potential of the EA method and LbL assembly for the composite formation mentioned above, there are still huge potentials and room for further development in the novel fabrication of composite materials. With the ever-increasing demand for AM, sustainable development, and the creation of novel materials, EA and LbL techniques will continue to play significant roles in every aspect of composite materials engineering. Here onward, prospective outlooks and future research directions involving new materials development using EA and LbL methods are described.

\subsection{Novel Composites for Additive Manufacturing}

Despite the numerous composites' fabrication mentioned above, there is still plenty of room for the design and formation of novel composites that exhibit the desired properties. Although AM has elevated manufacturing freedom to a new level, the lack of novel composites or processing materials have been the limiting factor in its development [52], such as for 3D printing and selective laser sintering technology. In order to fully maximize the potential of AM, novel materials can be created and fabricated using the EA method. The good controllability, homogeneity as well as scalability are key toward the large-scale production of novel materials for AM process.

\subsection{Multiple Homogenous Combinations for High-Entropy Materials Design}

In 2004, Yeh et al. reported the discovery of nanostructured high entropy alloys consisting of five or more principal constituent elements [83]. The high entropy alloys that exist in a random solution state due to their high mixing entropies demonstrated novel and unique properties that have not been reported before such as exceptional high-temperature strength, structural stability, and outstanding wear resistance $[84,85]$. This discovery has prompted intense research not only in metallic alloys but also in the development of new advanced materials using configurational disorders that possess unique properties such as entropy stabilized and high-entropy oxides [86-88]. Hence, to achieve homogeneity at the atomic and nanoscale level, controlled homogeneous mixtures have never been more crucial. This can be achieved through powder metallurgy, where a high level of powder homogeneity can promote the random effect required for the creation of a high-entropy state. Therefore, the EA method can play an important role in the future development of high-entropy materials.

\subsection{Homogenous Formation of Composite Granules}

In the design of nano-architectonic materials, precision in materials design and homogeneity can be achieved using nano-sized materials to enable improved homogeneity that can play a crucial role in the generation of unique properties. However, the use of nanoscale starting materials such as nanoparticles often leads to agglomeration issues in composite powders due to the high surface energy possessed by the particles [1]. Difficulty in handling nanoscale powders remains a huge challenge and is a hindrance toward the manufacturing process, not to mention the risk of health hazard if inhaled. This has led researchers to look for alternatives to produce the controlled formation of composite granules with a high level of homogeneity $[89,90]$. By controlling the surface charge of the materials using the EA method, the formation of granules with high homogeneity and good handleability can be achieved. Using modified surface-charge nanoparticles, controlled particle granulation via electrostatic interaction can be achieved to enable the spherical granule formation of several hundred micrometers, with better handleability compared to the nano-sized powder. Pringuet et al. have reported on the formation of $\mathrm{TiO}_{2}, \mathrm{ZrO}_{2}$, and $\mathrm{Al}_{2} \mathrm{O}_{3}$ granules with good homogeneity using PSS for the catalyst and filtering systems $[89,91,92]$. However, controlled granule formation with multiple constituent elements remains elusive. Detailed elucidation of the mechanism and surface-charge control parameter is crucial for further development in composite granule formation. This understanding will allow better homogeneous designs of powder mixtures through the granulation process for AM [52]. 


\subsection{Self-Cleaning and Antiviral Surfaces}

With the lesson learned from the current coronavirus pandemic that affected everyone globally, it is important to develop surfaces and interfaces with unique properties such as superhydrophobicity and antiviral/antibacterial properties for infection prevention [93]. The creation of artificial surfaces with antiviral mechanisms such as direct disinfection, indirect disinfection, and receptor inactivation as shown in Figure 14, could be employed through materials engineering [93]. The EA method can be used in the incorporation of surfactant and virucides on a complex geometric surface, morphologically engineered surface and surface hetero-coating as shown in Figure 14b. These strategies are useful in the generation of desired surface properties with antiviral/bacterial effect in the long-term combat against current and future outbreaks. The versatility of the EA and LbL methods in wetting property alteration [94-96], along with the simple incorporation of antiviral materials such Ag nanoparticles or other disinfectant materials, are important in the creation of self-cleaning materials for protective equipment, personal devices, clothing, and medical apparatus that are essential in the new normal lifestyle, which we are all already accustomed to.

\section{Types of antiviral surfaces}

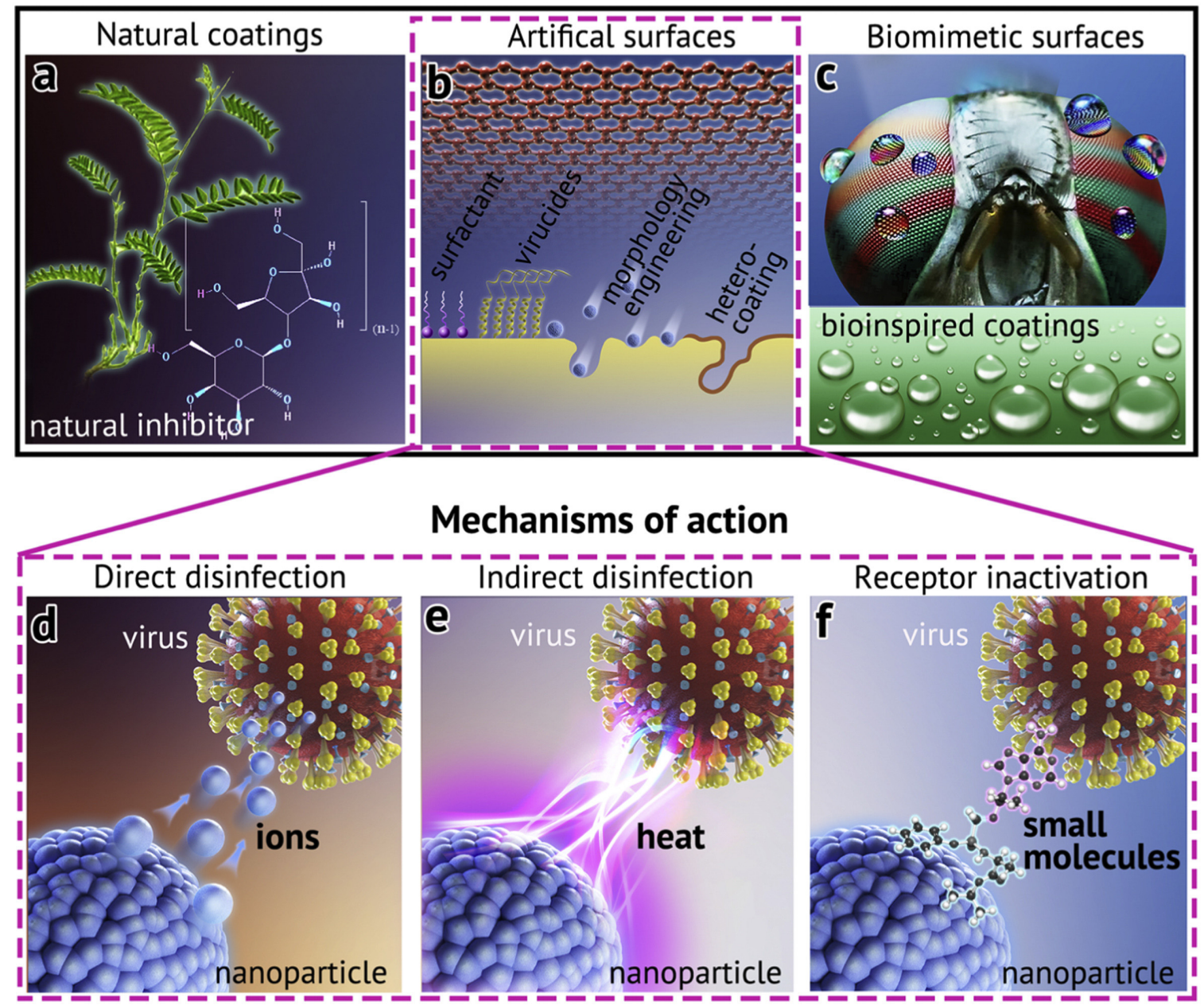

Figure 14. Promising antiviral coatings based on the selection of materials and nanostructured surface engineering to promote antiviral action mechanisms. Reprinted with permission from [93], copyright (2020) Elsevier. 


\subsection{Composite Membranes for Water Treatment}

With the rapid rate of industrial development, the world is facing severe water contamination and scarcity issues. Taking into consideration the abundance of seawater, researchers have begun to convert seawater to usable freshwater through desalination technology [97]. The LbL assembly is deemed as a promising technique for water desalination through the formation of multi-bipolar ultrathin membranes. The feasibility of controlling the membrane assembly through electrostatic interactions will enable novel membrane fabrication with specific ion rejection selectivity. In addition, it has been recently demonstrated that cross-linked LbL membranes could be fabricated for forward osmosis using a double-skin that also possesses antifouling properties for desalination purposes [98].

Water contamination with heavy metals such as chromium (VI), arsenic, and lead pose a serious health threat upon consumption. Many heavy metal mitigation studies are ongoing with the aim of achieving water sustainability. One of such methods is through the use of metal oxides for the adsorption and reduction of harmful heavy metals [99-102]. In future developments, it is also envisaged that the EA and LbL methods would be useful in the composite and membrane development for heavy metal ion removal due to its versatility in the modification of hydrophilicity and assembly processes [103].

\section{Conclusions}

In this review, a brief introduction of the EA and LbL methods was briefly described, followed by the description of the recent developments and applications of EA in composite formation. The versatility of the EA method has proven its importance in the bottom-up assembly of composite materials with good control in the tailoring of nano- and microstructures generating novel properties and functionalities. Since the discovery of the EA method, it has been used for various applications, and with the current trend of sustainable development with more focus on renewable energy and AM technology, this timely review surveys, describes, and revisits the huge potentials of EA for novel materials fabrication in a low environmental load manner. The low cost, simplicity, as well as the low environmental load of the EA method is well-aligned with the global SDGs and could a play significant role in the further development of sustainable technologies in various fields. In the wrap up, prospective outlooks and opportunities for future materials development, which will be essential in AM, creation of new-class materials, infectious disease prevention and water sustainability are also described.

Author Contributions: Conceptualization, H.M. and W.K.T.; methodology, H.M., A.Y. and W.K.T.; validation, H.M., A.Y. and W.K.T.; formal analysis, H.M. and W.K.T.; investigation, A.Y.; resources, H.M.; data curation, W.K.T.; writing —original draft preparation, W.K.T.; writing — review and editing, H.M. and A.Y.; visualization, W.K.T.; supervision, H.M.; project administration, A.Y.; funding acquisition, H.M. All authors have read and agreed to the published version of the manuscript.

Funding: Hiroyuki Muto and Wai Kian Tan would like to acknowledge the funding from the Japan Society for Promotion of Science (JSPS) Grant-in-Aid for Scientific Research JP18H01706, KAKENHI Early-Career Scientist JP18K14013 and Science of New-Class of Materials Based on Elemental Multiplicity and Heterogeneity (Grant No. 18H05452) from Ministry of Education, Culture, Sports, Science and Technology (MEXT), Japan.

Acknowledgments: Support by Toyohashi University of Technology Research Promotional Research Fund and The Naito Foundations are acknowledged.

Conflicts of Interest: The authors declare no conflict of interest.

\section{References}

1. Tan, W.K.; Araki, Y.; Yokoi, A.; Kawamura, G.; Matsuda, A.; Muto, H. Micro- and Nano-assembly of Composite Particles by Electrostatic Adsorption. Nanoscale Res. Lett. 2019, 14, 297. [CrossRef] [PubMed]

2. Subramaniam, M.N.; Goh, P.S.; Lau, W.J.; Ismail, A.F. The Roles of Nanomaterials in Conventional and Emerging Technologies for Heavy Metal Removal: A State-of-the-Art Review. Nanomaterials 2019, 9, 625. [CrossRef] [PubMed] 
3. Ariga, K.; Nakanishi, T.; Hill, J.P. Self-assembled microstructures of functional molecules. Curr. Opin. Colloid Interface Sci. 2007, 12, 106-120. [CrossRef]

4. Caruso, F.; Lichtenfeld, H.; Giersig, M.; Möhwald, H. Electrostatic Self-Assembly of Silica Nanoparticle-Polyelectrolyte Multilayers on Polystyrene Latex Particles. J. Am. Chem. Soc. 1998, 120, 8523-8524. [CrossRef]

5. Wu, C.; Aslan, S.; Gand, A.; Wolenski, J.S.; Pauthe, E.; Van Tassel, P.R. Porous Nanofilm Biomaterials Via Templated Layer-by-Layer Assembly. Adv. Funct. Mater. 2013, 23, 66-74. [CrossRef]

6. Ariga, K.; Lvov, Y.M.; Kawakami, K.; Ji, Q.; Hill, J.P. Layer-by-layer self-assembled shells for drug delivery. Adv. Drug Deliv. Rev. 2011, 63, 762-771. [CrossRef] [PubMed]

7. Ariga, K.; Malgras, V.; Ji, Q.; Zakaria, M.B.; Yamauchi, Y. Coordination nanoarchitectonics at interfaces between supramolecular and materials chemistry. Coord. Chem. Rev. 2016, 320-321, 139-152. [CrossRef]

8. Yokoi, A.; Tan, W.K.; Kuroda, T.; Kawamura, G.; Matsuda, A.; Muto, H. Design of Heat-Conductive hBN-PMMA Composites by Electrostatic Nano-Assembly. Nanomaterials 2020, 10, 134. [CrossRef] [PubMed]

9. Tan, W.K.; Yokoi, A.; Kawamura, G.; Matsuda, A.; Muto, H. PMMA-ITO Composite Formation via Electrostatic Assembly Method for Infra-Red Filtering. Nanomaterials 2019, 9, 886. [CrossRef] [PubMed]

10. Tan, W.K.; Tsuzuki, K.; Yokoi, A.; Kawamura, G.; Matsuda, A.; Muto, H. Formation of porous $\mathrm{Al}_{2} \mathrm{O}_{3}-\mathrm{SiO}_{2}$ composite ceramics by electrostatic assembly. J. Ceram. Soc. Jpn. 2020, 128, 605-610. [CrossRef]

11. Fenoy, G.E.; Van der Schueren, B.; Scotto, J.; Boulmedais, F.; Ceolín, M.R.; Bégin-Colin, S.; Bégin, D.; Marmisollé, W.A.; Azzaroni, O. Layer-by-layer assembly of iron oxide-decorated few-layer graphene/PANI:PSS composite films for high performance supercapacitors operating in neutral aqueous electrolytes. Electrochim. Acta 2018, 283, 1178-1187. [CrossRef]

12. Zhang, X.; Chen, H.; Zhang, H. Layer-by-layer assembly: From conventional to unconventional methods. Chem. Commun. 2007, 1395-1405. [CrossRef] [PubMed]

13. Decher, G.; Hong, J.D.; Schmitt, J. Buildup of ultrathin multilayer films by a self-assembly process: III. Consecutively alternating adsorption of anionic and cationic polyelectrolytes on charged surfaces. Thin Solid Film. 1992, 210-211, 831-835. [CrossRef]

14. Decher, G. Fuzzy Nanoassemblies: Toward Layered Polymeric Multicomposites. Science 1997, 277, $1232-1237$. [CrossRef]

15. Rydzek, G.; Ji, Q.; Li, M.; Schaaf, P.; Hill, J.P.; Boulmedais, F.; Ariga, K. Electrochemical nanoarchitectonics and layer-by-layer assembly: From basics to future. Nano Today 2015, 10, 138-167. [CrossRef]

16. Boudou, T.; Crouzier, T.; Ren, K.; Blin, G.; Picart, C. Multiple functionalities of polyelectrolyte multilayer films: New biomedical applications. Adv. Mater. 2010, 22, 441-467. [CrossRef]

17. Ren, K.-F.; Hu, M.; Zhang, H.; Li, B.-C.; Lei, W.-X.; Chen, J.-Y.; Chang, H.; Wang, L.-M.; Ji, J. Layer-by-layer assembly as a robust method to construct extracellular matrix mimic surfaces to modulate cell behavior. Prog. Polym. Sci. 2019, 92, 1-34. [CrossRef]

18. Wang, F.; Wang, J.; Zhai, Y.; Li, G.; Li, D.; Dong, S. Layer-by-layer assembly of biologically inert inorganic ions/DNA multilayer films for tunable DNA release by chelation. J. Control. Release 2008, 132, 65-73. [CrossRef]

19. Guzman, E.; Mateos-Maroto, A.; Ruano, M.; Ortega, F.; Rubio, R.G. Layer-by-Layer polyelectrolyte assemblies for encapsulation and release of active compounds. Adv. Colloid Interface Sci 2017, 249, 290-307. [CrossRef] [PubMed]

20. Guzman, E.; Rubio, R.G.; Ortega, F. A closer physico-chemical look to the Layer-by-Layer electrostatic self-assembly of polyelectrolyte multilayers. Adv. Colloid Interface Sci. 2020, 282, 102197. [CrossRef]

21. Guzmán, E.; Ortega, F.; Baghdadli, N.; Luengo, G.S.; Rubio, R.G. Effect of the molecular structure on the adsorption of conditioning polyelectrolytes on solid substrates. Colloids Surf. A Physicochem. Eng. Asp. 2011, 375, 209-218. [CrossRef]

22. Guzmán, E.; Ritacco, H.A.; Ortega, F.; Rubio, R.G. Growth of Polyelectrolyte Layers Formed by Poly(4-styrenesulfonate sodium salt) and Two Different Polycations: New Insights from Study of Adsorption Kinetics. J. Phys. Chem. C 2012, 116, 15474-15483. [CrossRef]

23. Ariga, K.; Lee, M.V.; Mori, T.; Yu, X.Y.; Hill, J.P. Two-dimensional nanoarchitectonics based on self-assembly. Adv. Colloid Interface Sci. 2010, 154, 20-29. [CrossRef] [PubMed]

24. Lvov, Y.; Ariga, K.; Ichinose, I.; Kunitake, T. Assembly of Multicomponent Protein Films by Means of Electrostatic Layer-by-Layer Adsorption. J. Am. Chem. Soc. 1995, 117, 6117-6123. [CrossRef] 
25. Shrestha, L.K.; Mori, T.; Ariga, K. Dynamic nanoarchitectonics: Supramolecular polymorphism and differentiation, shape-shifter and hand-operating nanotechnology. Curr. Opin. Colloid Interface Sci. 2018, 35, 68-80. [CrossRef]

26. Nakanishi, W.; Minami, K.; Shrestha, L.K.; Ji, Q.; Hill, J.P.; Ariga, K. Bioactive nanocarbon assemblies: Nanoarchitectonics and applications. Nano Today 2014, 9, 378-394. [CrossRef]

27. Ariga, K.; Mori, T.; Akamatsu, M.; Hill, J.P. Two-dimensional nanofabrication and supramolecular functionality controlled by mechanical stimuli. Thin Solid Film. 2014, 554, 32-40. [CrossRef]

28. Angelatos, A.S.; Katagiri, K.; Caruso, F. Bioinspired colloidal systems vialayer-by-layer assembly. Soft Matter 2006, 2, 18-23. [CrossRef]

29. Krishnan, V.; Sakakibara, K.; Mori, T.; Hill, J.P.; Ariga, K. Manipulation of thin film assemblies: Recent progress and novel concepts. Curr. Opin. Colloid Interface Sci. 2011, 16, 459-469. [CrossRef]

30. Tan, W.K.; Hakiri, N.; Yokoi, A.; Kawamura, G.; Matsuda, A.; Muto, H. Controlled microstructure and mechanical properties of $\mathrm{Al}_{2} \mathrm{O}_{3}$-based nanocarbon composites fabricated by electrostatic assembly method. Nanoscale Res. Lett. 2019, 14, 245. [CrossRef]

31. Tan, W.K.; Shigeta, Y.; Yokoi, A.; Kawamura, G.; Matsuda, A.; Muto, H. Investigation of the anchor layer formation on different substrates and its feasibility for optical properties control by aerosol deposition. Appl. Surf. Sci. 2019, 483, 212-218. [CrossRef]

32. Kuwana, T.; Tan, W.K.; Yokoi, A.; Kawamura, G.; Matsuda, A.; Muto, H. Fabrication of Carbon-decorated $\mathrm{Al}_{2} \mathrm{O}_{3}$ Composite Powders using Cellulose Nanofiber for Selective Laser Sintering. J. Jpn. Soc. Powder Powder Metall. 2019, 66, 168-173. [CrossRef]

33. Hamasaki, N.; Yamaguchi, S.; Use, S.; Kawashima, T.; Muto, H.; Nagao, M.; Hozumi, N.; Murakami, Y. Electrical and Thermal Properties of PMMA/h-BN Composite Material Produced by Electrostatic Adsorption Method. IEEJ Trans. Fundam. Mater. 2019, 139, 60-65. [CrossRef]

34. Muto, H.; Hakiri, N.; Phuc, N.H.H.; Kawamura, G.; Matsuda, A. Transparent Conductive CNT/PMMA Nanocomposite Via Electrostatic Adsorption Technique. ECS Trans. 2013, 50, 165-169. [CrossRef]

35. Yamaguchi, S.; Hamasaki, N.; Use, S.; Kawashima, T.; Muto, H.; Nagao, M.; Hozumi, N.; Murakami, Y. Influence of PMMA and h-BN particles sizes on electrical and thermal properties of PMMA/h-BN composite materials produced by electrostatic adsorption method. In Proceedings of the 2017 IEEE Conference on Electrical Insulation and Dielectric Phenomenon (CEIDP), Fort Worth, TX, USA, 22-25 October 2017; pp. 245-248.

36. Stuart, M.A.C.; Hoogendam, C.W.; Keizer, A.d. Kinetics of polyelectrolyte adsorption. J. Phys. Condens. Matter 1997, 9, 7767-7783. [CrossRef]

37. Qi, Y.; Qin, K.; Zou, Y.; Lin, L.; Jian, Z.; Chen, W. Flexible electrochromic thin films with ultrafast responsion based on exfoliated V2O5 nanosheets/graphene oxide via layer-by-layer assembly. Appl. Surf. Sci. 2020, 514. [CrossRef]

38. Liu, X.Q.; Fourel, L.; Dalonneau, F.; Sadir, R.; Leal, S.; Lortat-Jacob, H.; Weidenhaupt, M.; Albiges-Rizo, C.; Picart, C. Biomaterial-enabled delivery of SDF-1alpha at the ventral side of breast cancer cells reveals a crosstalk between cell receptors to promote the invasive phenotype. Biomaterials 2017, 127, 61-74. [CrossRef] [PubMed]

39. Kumar, R.; Sahoo, S.; Joanni, E.; Singh, R.K.; Tan, W.K.; Kar, K.K.; Matsuda, A. Recent progress in the synthesis of graphene and derived materials for next generation electrodes of high performance lithium ion batteries. Prog. Energy Combust. Sci. 2019, 75, 100786. [CrossRef]

40. Phuc, N.H.H.; Takaki, M.; Muto, H.; Reiko, M.; Kazuhiro, H.; Matsuda, A. Sulfur-Carbon Nano Fiber Composite Solid Electrolyte for All-Solid-State Li-S Batteries. ACS Appl. Energy Mater. 2020, 3, 1569-1573. [CrossRef]

41. Tan, W.K.; Asami, K.; Maeda, Y.; Hayashi, K.; Kawamura, G.; Muto, H.; Matsuda, A. Facile formation of Fe3O4-particles decorated carbon paper and its application for all-solid-state rechargeable Fe-air battery. Appl. Surf. Sci. 2019, 486, 257-264. [CrossRef]

42. Kumar, R.; Sahoo, S.; Joanni, E.; Singh, R.K.; Maegawa, K.; Tan, W.K.; Kawamura, G.; Kar, K.K.; Matsuda, A. Heteroatom doped graphene engineering for energy storage and conversion. Mater. Today 2020. [CrossRef]

43. Hong, X.; Zhang, B.; Murphy, E.; Zou, J.; Kim, F. Three-dimensional reduced graphene oxide/polyaniline nanocomposite film prepared by diffusion driven layer-by-layer assembly for high-performance supercapacitors. J. Power Sources 2017, 343, 60-66. [CrossRef] 
44. Nbelayim, P.; Ashida, Y.; Maegawa, K.; Kawamura, G.; Muto, H.; Matsuda, A. Preparation and Characterization of Stable and Active Pt@TiO2 Core-Shell Nanoparticles as Electrocatalyst for Application in PEMFCs. ACS Appl. Energy Mater. 2020, 3, 3269-3281. [CrossRef]

45. Che, Q.; Fan, H.; Duan, X.; Feng, F.; Mao, W.; Han, X. Layer by layer self-assembly fabrication of high temperature proton exchange membrane based on ionic liquids and polymers. J. Mol. Liq. 2018, 269, 666-674. [CrossRef]

46. Ooi, Y.X.; Ya, K.Z.; Maegawa, K.; Tan, W.K.; Kawamura, G.; Muto, H.; Matsuda, A. CHS-WSiA doped hexafluoropropylidene-containing polybenzimidazole composite membranes for medium temperature dry fuel cells. Int. J. Hydrog. Energy 2019, 44, 32201-32209. [CrossRef]

47. Ooi, Y.X.; Ya, K.Z.; Maegawa, K.; Tan, W.K.; Kawamura, G.; Muto, H.; Matsuda, A. Incorporation of titanium pyrophosphate in polybenzimidazole membrane for medium temperature dry PEFC application. Solid State Ion. 2020, 344. [CrossRef]

48. Maegawa, K.; Zay Ya, K.; Tan, W.K.; Kawamura, G.; Hattori, T.; Muto, H.; Matsuda, A. Enhancement of interfacial property by novel solid ionomer $\mathrm{CsHSO}_{4}-\mathrm{H}_{4} \mathrm{SiW}_{12} \mathrm{O}_{40}$ for the three-phase interface of a medium-temperature anhydrous fuel cell. Mater. Lett. 2019, 253, 201-204. [CrossRef]

49. Meemuk, C.; Chirachanchai, S. Constructing polymeric proton donor and proton acceptor in layer-by-layer structure for efficient proton transfer in PEMFC. Int. J. Hydrog. Energy 2016, 41, 4765-4772. [CrossRef]

50. Ibbett, J.; Tafazzolimoghaddam, B.; Hernandez Delgadillo, H.; Curiel-Sosa, J.L. What triggers a microcrack in printed engineering parts produced by selective laser sintering on the first place? Mater. Des. 2015, 88, 588-597. [CrossRef]

51. Sofia, D.; Barletta, D.; Poletto, M. Laser sintering process of ceramic powders: The effect of particle size on the mechanical properties of sintered layers. Addit. Manuf. 2018, 23, 215-224. [CrossRef]

52. Tofail, S.A.M.; Koumoulos, E.P.; Bandyopadhyay, A.; Bose, S.; O’Donoghue, L.; Charitidis, C. Additive manufacturing: Scientific and technological challenges, market uptake and opportunities. Mater. Today 2018, 21, 22-37. [CrossRef]

53. Chen, Z.; Li, Z.; Li, J.; Liu, C.; Lao, C.; Fu, Y.; Liu, C.; Li, Y.; Wang, P.; He, Y. 3D printing of ceramics: A review. J. Eur. Ceram. Soc. 2019, 39, 661-687. [CrossRef]

54. Tan, W.K.; Matsuzaki, T.; Yokoi, A.; Kawamura, G.; Matsuda, A.; Muto, H. Improved green body strength using PMMA- $\mathrm{Al}_{2} \mathrm{O}_{3}$ composite particles fabricated via electrostatic assembly. Nano Express 2020. [CrossRef]

55. Hwa, L.C.; Rajoo, S.; Noor, A.M.; Ahmad, N.; Uday, M.B. Recent advances in 3D printing of porous ceramics: A review. Curr. Opin. Solid State Mater. Sci. 2017, 21, 323-347. [CrossRef]

56. Lee, J.-Y.; An, J.; Chua, C.K. Fundamentals and applications of 3D printing for novel materials. Appl. Mater. Today 2017, 7, 120-133. [CrossRef]

57. Amin Yavari, S.; Croes, M.; Akhavan, B.; Jahanmard, F.; Eigenhuis, C.C.; Dadbakhsh, S.; Vogely, H.C.; Bilek, M.M.; Fluit, A.C.; Boel, C.H.E.; et al. Layer by layer coating for bio-functionalization of additively manufactured meta-biomaterials. Addit. Manuf. 2020, 32. [CrossRef]

58. Shin, J.-H.; Choi, J.; Kim, M.; Hong, S.-H. Comparative study on carbon nanotube- and reduced graphene oxide-reinforced alumina ceramic composites. Ceram. Int. 2018, 44, 8350-8357. [CrossRef]

59. Zhan, G.-D.; Kuntz, J.D.; Wan, J.; Mukherjee, A.K. Single-wall carbon nanotubes as attractive toughening agents in alumina-based nanocomposites. Nat. Mater. 2002, 2, 38. [CrossRef]

60. Kumari, L.; Zhang, T.; Du, G.; Li, W.; Wang, Q.; Datye, A.; Wu, K. Thermal properties of CNT-Alumina nanocomposites. Compos. Sci. Technol. 2008, 68, 2178-2183. [CrossRef]

61. Dionigi, C.; Ivanovska, T.; Ortolani, L.; Morandi, V.; Ruani, G. Electrically conductive gamma-alumina/amorphous carbon nano-composite foams. J. Alloy. Compd. 2017, 694, 921-928. [CrossRef]

62. Petit, C.; Montanaro, L.; Palmero, P. Functionally graded ceramics for biomedical application: Concept, manufacturing, and properties. Int. J. Appl. Ceram. Technol. 2018, 15, 820-840. [CrossRef]

63. Meille, S.; Lombardi, M.; Chevalier, J.; Montanaro, L. Mechanical properties of porous ceramics in compression: On the transition between elastic, brittle, and cellular behavior. J. Eur. Ceram. Soc. 2012, 32, 3959-3967. [CrossRef]

64. Ali, M.S.; Hanim, M.A.A.; Tahir, S.M.; Jaafar, C.N.A.; Norkhairunnisa, M.; Matori, K.A. Preparation and characterization of porous alumina ceramics using different pore agents. J. Ceram. Soc. Jpn. 2017, 125, 402-412. [CrossRef] 
65. Ohji, T.; Fukushima, M. Macro-porous ceramics: Processing and properties. Int. Mater. Rev. 2012, 57, $115-131$. [CrossRef]

66. Akedo, J. Room Temperature Impact Consolidation (RTIC) of Fine Ceramic Powder by Aerosol Deposition Method and Applications to Microdevices. J. Therm. Spray Technol. 2008, 17, 181-198. [CrossRef]

67. Akedo, J. Room temperature impact consolidation and application to ceramic coatings: Aerosol deposition method. J. Ceram. Soc. Jpn. 2020, 128, 101-116. [CrossRef]

68. Adamczyk, J.; Fuierer, P. Compressive stress in nano-crystalline titanium dioxide films by aerosol deposition. Surf. Coat. Technol. 2018, 350, 542-549. [CrossRef]

69. Cho, M.-Y.; Park, S.-J.; Kim, S.-M.; Lee, D.-W.; Kim, H.-K.; Koo, S.-M.; Moon, K.-S.; Oh, J.-M. Hydrophobicity and transparency of $\mathrm{Al}_{2} \mathrm{O}_{3}$-based poly-tetra-fluoro-ethylene composite thin films using aerosol deposition. Ceram. Int. 2018, 44, 16548-16555. [CrossRef]

70. Exner, J.; Schubert, M.; Hanft, D.; Stöcker, T.; Fuierer, P.; Moos, R. Tuning of the electrical conductivity of $\mathrm{Sr}(\mathrm{Ti}, \mathrm{Fe}) \mathrm{O}_{3}$ oxygen sensing films by aerosol co-deposition with $\mathrm{Al}_{2} \mathrm{O}_{3}$. Sens. Actuators B Chem. 2016, 230, 427-433. [CrossRef]

71. Hahn, B.-D.; Lee, J.-M.; Park, D.-S.; Choi, J.-J.; Ryu, J.; Yoon, W.-H.; Lee, B.-K.; Shin, D.-S.; Kim, H.-E. Aerosol deposition of silicon-substituted hydroxyapatite coatings for biomedical applications. Thin Solid Film. 2010, 518, 2194-2199. [CrossRef]

72. Akedo, J. Aerosol Deposition of Ceramic Thick Films at Room Temperature: Densification Mechanism of Ceramic Layers. J. Am. Ceram. Soc. 2006, 89, 1834-1839. [CrossRef]

73. Akedo, J.; Nakano, S.; Park, J.; Baba, S.; Ashida, K. The aerosol deposition method; For production of high performance micro devices with low cost and low energy consumption. Synth. Engl. Ed. 2008, 1, 121-130. [CrossRef]

74. Cierech, M.; Osica, I.; Kolenda, A.; Wojnarowicz, J.; Szmigiel, D.; Lojkowski, W.; Kurzydlowski, K.; Ariga, K.; Mierzwinska-Nastalska, E. Mechanical and Physicochemical Properties of Newly Formed ZnO-PMMA Nanocomposites for Denture Bases. Nanomaterials 2018, 8, 305. [CrossRef] [PubMed]

75. Arul, K.T.; Ramanjaneyulu, M.; Ramachandra Rao, M.S. Energy harvesting of PZT/PMMA composite flexible films. Curr. Appl. Phys. 2019, 19, 375-380. [CrossRef]

76. Nayak, D.; Choudhary, R.B. Augmented optical and electrical properties of PMMA-ZnS nanocomposites as emissive layer for OLED applications. Opt. Mater. 2019, 91, 470-481. [CrossRef]

77. Sugumaran, S.; Bellan, C.S. Transparent nano composite PVA-TiO2 and PMMA-TiO2 thin films: Optical and dielectric properties. Optik 2014, 125, 5128-5133. [CrossRef]

78. Arlindo, E.P.S.; Lucindo, J.A.; Bastos, C.M.O.; Emmel, P.D.; Orlandi, M.O. Electrical and Optical Properties of Conductive and Transparent ITO@PMMA Nanocomposites. J. Phys. Chem. C 2012, 116, 12946-12952. [CrossRef]

79. Arlindo, E.P.S.; Orlandi, M.O. Study ITO@PMMA Composites by Transmission Electron Microscopy. MRS Proc. 2011, 1312. [CrossRef]

80. Matsui, H.; Furuta, S.; Hasebe, T.; Tabata, H. Plasmonic-Field Interactions at Nanoparticle Interfaces for Infrared Thermal-Shielding Applications Based on Transparent Oxide Semiconductors. ACS Appl. Mater. Interfaces 2016, 8, 11749-11757. [CrossRef]

81. Matsui, H.; Tabata, H. Assembled Films of Sn-Doped $\operatorname{In}_{2} \mathrm{O}_{3}$ Plasmonic Nanoparticles on High-Permittivity Substrates for Thermal Shielding. ACS Appl. Nano Mater. 2019, 2, 2806-2816. [CrossRef]

82. Matsui, H.; Tabata, H. Infrared Solar Thermal-Shielding Applications Based on Oxide Semiconductor Plasmonics. In Nanoplasmonics_Fundamentals and Applications; IntechOpen: London, UK, 2017. [CrossRef]

83. Yeh, J.-W.; Chen, S.-K.; Lin, S.-J.; Gan, J.-Y.; Chin, T.-S.; Shun, T.-T.; Tsau, C.-H.; Chang, S.-Y. Nanostructured High-Entropy Alloys with Multiple Principal Elements: Novel Alloy Design Concepts and Outcomes. Adv. Eng. Mater. 2004, 6, 299-303. [CrossRef]

84. Tsai, M.-H.; Yeh, J.-W. High-Entropy Alloys: A Critical Review. Mater. Res. Lett. 2014, 2, 107-123. [CrossRef]

85. Joo, S.H.; Bae, J.W.; Park, W.Y.; Shimada, Y.; Wada, T.; Kim, H.S.; Takeuchi, A.; Konno, T.J.; Kato, H.; Okulov, I.V. Beating Thermal Coarsening in Nanoporous Materials via High-Entropy Design. Adv. Mater. 2020, 32, e1906160. [CrossRef] [PubMed]

86. Rost, C.M.; Sachet, E.; Borman, T.; Moballegh, A.; Dickey, E.C.; Hou, D.; Jones, J.L.; Curtarolo, S.; Maria, J.P. Entropy-stabilized oxides. Nat. Commun. 2015, 6, 8485. [CrossRef] [PubMed] 
87. Sharma, A.S.; Yadav, S.; Biswas, K.; Basu, B. High-entropy alloys and metallic nanocomposites: Processing challenges, microstructure development and property enhancement. Mater. Sci. Eng. R Rep. 2018, 131, 1-42. [CrossRef]

88. Zhang, R.-Z.; Reece, M.J. Review of high entropy ceramics: Design, synthesis, structure and properties. J. Mater. Chem. A 2019, 7, 22148-22162. [CrossRef]

89. Pringuet, A.; Pagnoux, C.; Videcoq, A.; Baumard, J.-F. Granulating Titania Powder by Colloidal Route Using Polyelectrolytes. Langmuir 2008, 24, 10702-10708. [CrossRef]

90. Pitt, K.; Peña, R.; Tew, J.D.; Pal, K.; Smith, R.; Nagy, Z.K.; Litster, J.D. Particle design via spherical agglomeration: A critical review of controlling parameters, rate processes and modelling. Powder Technol. 2018, 326, 327-343. [CrossRef]

91. Pringuet, A.; Belounis, F.; Pagnoux, C. Use of Polyelectrolyte Complexes as a Binding Agent in the Granulation Process of Titania Particles. J. Am. Ceram. Soc. 2011, 94, 729-735. [CrossRef]

92. Pringuet, A.; Pagnoux, C.; Videcoq, A.; Baumard, J.-F. Granulating fine powders into millimetric spheres with a multiscale porosity: The case of titania. Microporous Mesoporous Mater. 2011, 140, 17-24. [CrossRef]

93. Sun, Z.; Ostrikov, K. Future antiviral surfaces: Lessons from COVID-19 pandemic. Sustain. Mater. Technol. 2020, 25. [CrossRef]

94. Alotaibi, H.F.; Al Thaher, Y.; Perni, S.; Prokopovich, P. Role of processing parameters on surface and wetting properties controlling the behaviour of layer-by-layer coated nanoparticles. Curr. Opin. Colloid Interface Sci. 2018, 36, 130-142. [CrossRef]

95. Ghostine, R.A.; Jisr, R.M.; Lehaf, A.; Schlenoff, J.B. Roughness and Salt Annealing in a Polyelectrolyte Multilayer. Langmuir 2013, 29, 11742-11750. [CrossRef] [PubMed]

96. Huang, X.; Zacharia, N.S. Functional polyelectrolyte multilayer assemblies for surfaces with controlled wetting behavior. J. Appl. Polym. Sci. 2015, 132. [CrossRef]

97. Xu, G.-R.; Wang, S.-H.; Zhao, H.-L.; Wu, S.-B.; Xu, J.-M.; Li, L.; Liu, X.-Y. Layer-by-layer (LBL) assembly technology as promising strategy for tailoring pressure-driven desalination membranes. J. Membr. Sci. 2015, 493, 428-443. [CrossRef]

98. Qi, S.; Qiu, C.Q.; Zhao, Y.; Tang, C.Y. Double-skinned forward osmosis membranes based on layer-by-layer assembly-FO performance and fouling behavior. J. Membr. Sci. 2012, 405-406, 20-29. [CrossRef]

99. Budiman, F.; Bashirom, N.; Tan, W.K.; Razak, K.A.; Matsuda, A.; Lockman, Z. Rapid nanosheets and nanowires formation by thermal oxidation of iron in water vapour and their applications as $\mathrm{Cr}(\mathrm{VI})$ adsorbent. Appl. Surf. Sci. 2016, 380, 172-177. [CrossRef]

100. Alias, N.; Rosli, S.A.; Bashirom, N.; Rozana, M.; Tan, W.K.; Kawamura, G.; Nbelayim, P.; Matsuda, A.; Hussain, Z.; Lockman, Z. Chapter eight-Oxide nanotubes formation by anodic process and their application in photochemical reactions for heavy metal removal. In Nanostructured Anodic Metal Oxides; Sulka, G.D., Ed.; Elsevier: Amsterdam, The Netherlands, 2020; pp. 277-303. [CrossRef]

101. Bashirom, N.; Kian, T.W.; Kawamura, G.; Matsuda, A.; Razak, K.A.; Lockman, Z. Sunlight activated anodic freestanding $\mathrm{ZrO} 2$ nanotube arrays for $\mathrm{Cr}(\mathrm{VI})$ photoreduction. Nanotechnology 2018, 29, 375701. [CrossRef] [PubMed]

102. Bashirom, N.; Tan, W.K.; Kawamura, G.; Matsuda, A.; Lockman, Z. Comparison of ZrO2, TiO2, and $\alpha-\mathrm{Fe}_{2} \mathrm{O}_{3}$ nanotube arrays on $\mathrm{Cr}(\mathrm{VI})$ photoreduction fabricated by anodization of $\mathrm{Zr}$, Ti, and Fe foils. Mater. Res. Express 2020, 7. [CrossRef]

103. Hosseini, S.M.; Alibakhshi, H.; Jashni, E.; Parvizian, F.; Shen, J.N.; Taheri, M.; Ebrahimi, M.; Rafiei, N. A novel layer-by-layer heterogeneous cation exchange membrane for heavy metal ions removal from water. J. Hazard Mater. 2020, 381, 120884. [CrossRef]

Publisher's Note: MDPI stays neutral with regard to jurisdictional claims in published maps and institutional affiliations. 